\title{
Políticas de apoio à inovação em pequenas empresas: evidências sobre a experiência brasileira recente *
}

\author{
Ana Paula Macedo de Avellar** \\ Marisa dos Reis A. Botelho ${ }^{* * *}$
}

\begin{abstract}
Resumo
As políticas de apoio à inovação vêm fazendo parte da agenda econômica de países desenvolvidos e em desenvolvimento, destacando-se a proliferação de programas direcionados às empresas de pequeno porte. $\mathrm{O}$ objetivo do presente artigo é o de analisar a abrangência e efetividade dos atuais programas de apoio à inovação direcionados às pequenas empresas brasileiras. Elabora-se uma análise evolutiva da incidência dos programas sobre seu público alvo nos anos 2000, e da sua efetividade, por meio de indicadores de esforço e desempenho inovativos das empresas contempladas e não contempladas pelos programas, considerando-se também o recorte setorial. A análise empírica baseou-se em dados das últimas três edições da Pesquisa de Inovação Tecnológica (Pintec), de 2003, 2005 e 2008, realizadas pelo IBGE, obtidos mediante uma tabulação especial desenvolvida para o presente trabalho. Dentre os resultados encontrados verifica-se que o apoio às atividades inovativas das pequenas empresas tem crescido, tanto em termos de magnitude dos recursos envolvidos quanto em termos de diversificação dos instrumentos, promovendo um aprimoramento do esforço inovativo desse segmento representativo de empresas brasileiras.
\end{abstract}

Palavras-chave: Política de inovação; Pequenas empresas; Indústria brasileira; Pintec; Brasil.

\section{Abstract \\ Innovation policies in small firms: evidence from recent Brazilian experience}

Innovation policies have increasingly been part of the economic agenda of developed and developing countries, particularly through programs focused on small businesses. The objective of this paper is to analyze the scope and effectiveness of innovation policies in Brazil, with an emphasis on new tools to foster small business innovation. Analyzing Brazilian public policies focused on fostering innovation in small businesses, this paper presents, with a pioneering feature, the profile of firms that have access to public resources. It will also present the indicators of innovative effort and performance for those that benefited or not from public program resources, as well as considering a sectoral analysis. The empirical analysis is based on data from the last three issues of the Pesquisa de Inovação Tecnológica (Pintec 2003, 2005 and 2008), with the use of a tabulation developed by IBGE especially for this paper. The results suggest that the public support for the innovative activities of small businesses is growing in terms of the magnitude of the available resources as well as the diversification of instruments used, promoting improvements regarding the innovative efforts of this representative segment of Brazilian firms.

Keywords: Innovation policy; Small businesses; Brazilian industry; Pintec; Brazil. JEL O32, O38.

* Trabalho recebido em 14 de fevereiro de 2013 e aprovado em 14 de dezembro de 2014. Agradecimentos ao apoio da Fapemig (Fundação de Amparo à Pesquisa do Estado de Minas Gerais).

** Professora Adjunto 4 do Instituto de Economia da Universidade Federal de Uberlândia (UFU), Uberlândia, MG, Brasil / Pesquisadora do $\underline{\mathrm{CNPq}}$ (Conselho Nacional de Desenvolvimento Científico e Tecnológico) e Fapemig. E-mail: anaavellar@ie.ufu.br.

**** Professora Associado 4 do Instituto de Economia da Universidade Federal de Uberlândia, Uberlândia, MG, Brasil. E-mail: botelhomr@ufu.br. 


\section{Introdução}

A atividade de inovação como um motor para o desenvolvimento econômico foi destacada em diferentes trabalhos de pesquisa, especialmente a partir de desenvolvimentos teóricos do enfoque neo-schumpeteriano. Em um primeiro momento, estes trabalhos realçaram os gastos em pesquisa e desenvolvimento (P\&D) de empresas e países como a principal variável determinante das inovações, o que significou relacionar a atividade inovativa com as grandes empresas e sua capacidade de despender vultosas somas de recursos em pesquisa. $\mathrm{O}$ avanço do conhecimento empírico e teórico nesta temática mostrou que a atividade inovativa das empresas decorre de diversos elementos que interagem no processo produtivo, colocando os gastos em P\&D como um dos determinantes da atividade de inovação.

Os trabalhos empíricos que realizaram estudos mais sistemáticos das características da atividade inovativa dedicaram-se, entre outros aspectos, a apreender a relação entre inovação e porte das empresas. Os resultados encontrados por meio da utilização de diferentes metodologias não estabeleceram uma relação direta e linear entre a geração de inovações e o porte das empresas. A despeito da existência de resultados conflitantes, o avanço do conhecimento nesta temática mostrou que os determinantes da atividade de inovação diferem entre grandes e pequenas empresas, sendo necessário considerar, além de gastos formais em P\&D, outras fontes geradoras de conhecimento que se encontram na esfera de atuação das empresas, como as relações no interior das cadeias produtivas (fornecedores e clientes), as relações com instituições de ensino e pesquisa (universidades e centros tecnológicos/pesquisa), dentre outras de naturezas diversas (associações empresariais, sindicatos). Ademais, especificidades setoriais, localização geográfica e condições macroeconômicas adequadas, especialmente condições favoráveis de financiamento, apresentam-se como elementos essenciais na explicação da atividade inovativa em pequenas empresas.

A partir destas referências, as políticas industriais direcionaram-se crescentemente ao estímulo à inovação e, como tendência mais recente, destaca-se a proliferação de programas direcionados às empresas de pequeno porte, em países desenvolvidos e em desenvolvimento.

O objetivo do presente artigo é o de analisar a abrangência e efetividade dos atuais programas de apoio à inovação direcionados às pequenas empresas brasileiras. Para cumprir esse objetivo faz-se uma análise evolutiva da incidência dos programas sobre seu público alvo desde o início dos anos 2000, e da sua efetividade, por meio de indicadores de esforço e desempenho inovativos das empresas contempladas e não contempladas pelos programas, considerando-se também o recorte setorial. A análise empírica baseou-se em dados das Pintecs 2003, 2005 e 2008, realizadas pelo 
Instituto Brasileiro de Geografia e Estatística (IBGE), obtidos mediante uma tabulação especial desenvolvida para o presente trabalho.

Ao construir e analisar um conjunto de indicadores de esforço e desempenho inovativos para as empresas de pequeno porte brasileiras, o artigo contribui no entendimento do papel das políticas públicas para o desenvolvimento desse segmento empresarial. Ademais, as mudanças nas políticas públicas brasileiras ainda são muito recentes e, assim, pouco analisadas na literatura especializada.

$\mathrm{O}$ artigo estrutura-se em duas seções, além desta Introdução e das Considerações finais. A seção 1 apresenta a revisão da literatura concernente às características principais da atividade inovativa em empresas de pequeno porte, assim como a análise de resultados de programas de apoio à inovação avaliados por pesquisas divulgadas em periódicos científicos. A seção 2 contém um breve resumo das políticas direcionadas às pequenas empresas brasileiras nas últimas cinco décadas, com ênfase nas mudanças levadas a cabo a partir dos anos 2000, com a Política Industrial, Tecnológica e de Comércio Exterior (Pitce). A análise empírica do caso brasileiro é analisada na quarta seção, em que se apresentam os dados sobre o perfil das empresas contempladas e das não contempladas nos diversos programas, assim como indicadores de esforço e desempenho inovativos.

\section{Inovação, pequenas empresas e políticas públicas}

Pesquisas recentes de diferentes naturezas mostram a existência de uma significativa atividade de inovação em empresas de pequeno porte ${ }^{1}$. Os desenvolvimentos no campo da teoria neo-schumpeteriana permitiram caracterizar a inovação como um fenômeno complexo, cujos determinantes extrapolam os gastos formalizados em P\&D (Freeman, 1991; Lundvall, 1992). A identificação das interações estabelecidas pelas empresas nos seus processos produtivos como elementos cruciais para a atividade de inovação trouxe à tona importantes conhecimentos sobre como as empresas inovam na prática, o que significou dar um tratamento mais exaustivo às pesquisas e considerar aspectos que extrapolam a consideração apenas de proxies, como os gastos formalizados em P\&D e as patentes.

Para o segmento das pequenas empresas, as evidências empíricas coletadas mais recentemente demonstram que o conjunto de elementos que favorecem a sua atividade de inovação as diferenciam do segmento das grandes empresas. Há que se considerar os gastos não formalizados em P\&D e as diferentes interações que

(1) Não há uma classificação universal para o que seja esse segmento de empresas. Em alguns países, como no caso europeu, o foco das ações recai sobre as pequenas e médias empresas (até 250 empregados); nos EUA, considera-se o limite de 500 empregados. Nos países em desenvolvimento é comum o foco das políticas recair sobre as denominadas micro e pequenas empresas que, no caso da indústria brasileira, englobam empresas com até 99 empregados. Utilizar-se-á a denominação genérica de pequenas empresas (PEs) para referir-se ao segmento foco das políticas e, quando necessário, os devidos esclarecimentos serão feitos. 
favorecem e estimulam os mecanismos de aprendizagem, interações que combinam conhecimentos internos e externos e que se efetivam em relações com clientes/fornecedores, com empresas concorrentes, com universidades/centros de pesquisa, dentre outros. Estas interações apresentam diferenças setoriais e um forte conteúdo territorial, aspectos que têm sido tratados em trabalhos recentes ${ }^{2}$.

Em relação aos determinantes setoriais da inovação, Pavitt (1984), em trabalho pioneiro sobre o tema, mostrou que, em determinados setores de atividade, as pequenas e médias empresas apresentam participação relevante na geração de inovações. O aprofundamento da análise do autor, ao examinar os dados do SPRU (Science Policy Research Unit), o leva a destacar a importância das PMEs em setores caracterizados por alta oportunidade tecnológica, em especial os de maquinaria/engenharia mecânica e instrumentos. A conclusão principal do trabalho acerca deste tema é a de que "there is much more innovative activity amongst firms with fewer than 1000 employees than the R\&D statistics had let us to assume; (...) small firms continue to be innovative in supplying specialized production inputs, in symbiosis with large, innovative users" (Pavitt et al.,1987, p. 313).

$\mathrm{Na}$ mesma direção, Acs e Audretsch (1990) mostraram resultados que destacam a participação elevada de pequenas e médias empresas em diversos setores. Em 14 setores $^{3}$, entre os 34 considerados como os mais inovadores da indústria americana, a participação de PMEs (até 500 empregados) no total de inovações foi de aproximadamente $50 \%$.

Igualmente importantes para discutir a temática da inovação em PEs são os estudos que se dedicaram a apreender o papel do entorno territorial e dos ativos nele localizados. Estes ativos são um suporte à inovação mais importante para as PEs do que para as grandes empresas (GEs) que, em geral, encontram dificuldades financeiras para desenvolver internamente todo o conhecimento necessário à realização de inovações. O acesso às fontes externas de conhecimento é facilitado pela proximidade espacial, em virtude das possibilidades de obtenção e transmissão de conhecimentos tácitos em interações face a face advindas de relações econômicas, sociais e culturais que se desenvolvem em localidades específicas (Schmitz; Nadvi, 1999; Mytelka; Farinelli, 2000; Cassiolato; Lastres, 2003; Asheim; Gertler, 2006).

(2) Os primeiros estudos que se dedicaram a esta temática foram os que tentaram testar hipóteses identificadas com os primeiros trabalhos de J. Schumpeter, com realce para o papel das empresas de pequeno porte na geração de inovações, ou com os trabalhos da fase mais madura deste autor, que realça o papel das grandes empresas e seus laboratórios de P\&D. O conjunto destes trabalhos apresenta resultados díspares que corroboram, a depender da metodologia e da base de dados utilizada, as duas hipóteses. A análise destes trabalhos pioneiros por parte de alguns autores leva ao ponto de vista de que não faz sentido o teste dessas hipóteses, dado que a atividade de inovação difere entre grandes e pequenas empresas. A esse respeito ver Acs e Audretsh (1990); Santarelli;e Piergiovanni (1996); Vaona e Pianta (2008). Para uma síntese dos primeiros trabalhos dedicados ao tema, conferir Audretsch (2004).

(3) Classificação dos setores segundo o SIC (Standard Industrial Classification), ao nível de quatro dígitos. 
Outros elementos influenciam a atividade de inovação de pequenas empresas e vêm sendo considerados na literatura especializada. A questão do financiamento e de medidas indiretas de apoio às empresas de pequeno porte apresenta-se como aspecto de grande relevância, dadas as dificuldades estruturais que estas empresas possuem para acessar crédito. Trabalhos mais recentes indicam que as dificuldades de acesso ao crédito para o financiamento de P\&D em empresas de pequeno porte tendem a ser maiores do que o financiamento do investimento convencional. As razões repousam na maior incerteza e nos maiores riscos associados à busca de inovações, especialmente por parte de empresas que dispõem principalmente de ativos intangíveis, que é o caso das pequenas empresas de base tecnológica.

Problemas de acesso a financiamento por parte de PEs são relatados em diversos estudos (Fatoki; Smit, 2011; OECD, 2004, 2006; Beck; Demirguc-Kunt, 2006; Wu et al., 2008) que abarcam períodos e países diferentes, permitindo caracterizá-los como um elemento estrutural ao funcionamento dessas empresas.

A proposição principal é a da existência de um financing gap para as pequenas empresas, decorrente da baixa disponibilidade do sistema financeiro para conceder empréstimos a este segmento empresarial (OECD, 2006; Liming, 2011), em consonância com as proposições pioneiras de Steindl (1983; 1990). Este gap, embora seja comum a todos os países, tende a ser maior nas economias em desenvolvimento, devido à existência de sistemas financeiros menos complexos nestas economias. Como decorrência, coloca-se um importante papel para as políticas públicas, no sentido de tentar minimizar os problemas de acesso a financiamento para as empresas de pequeno porte.

A importância do setor público para o financiamento de PEs fica evidenciada quando se consideram pesquisas empíricas que mostram que a disponibilidade de financiamento apresenta efeitos positivos. Este é o caso do estudo realizado para empresas alemãs por Czarnitzki e Hottenrott (2011), a partir de uma amostra de 4017 empresas no período 1992-2002. Com a utilização de dados em painel, os autores demonstram que o crescimento da disponibilidade de fundos externos provoca um aumento do investimento em P\&D maior nas pequenas do que nas grandes empresas, o que evidencia que as empresas de menor porte são mais propensas a inovar quando melhora o acesso a fontes externas de financiamento.

Em suma, as evidências empíricas que sustentam a existência de uma importante atividade de inovação por parte de pequenas empresas, em conjunto com as dificuldades de acesso a financiamento, implicam em uma forte atuação do setor público, seja diretamente na concessão de empréstimos por meio de bancos e agências públicos, seja indiretamente, por meio de incentivos fiscais, estímulo à formação de mercados de capitais mais favoráveis às empresas de pequeno porte, 
dentre outros. Pode-se dizer que nas políticas tecnológicas e de inovação da quase totalidade dos países, parte importante das ações direcionam-se ao segmento das micro, pequenas e médias empresas ${ }^{4}$.

Dentre os instrumentos utilizados no âmbito das políticas de apoio, destacam-se os incentivos diretos na forma de recursos de subvenção econômica e de empréstimos subsidiados, de apoio à constituição de fundos de venture capital, as compras públicas, além de incentivos indiretos na forma de isenções fiscais. Estes últimos apresentam enorme variabilidade entre países, em consonância com a diversidade dos regimes fiscais, mesmo no caso dos países da União Europeia (OECD, 2010; COM, 2006).

Os países da América Latina também vêm implementando, na atualidade, um amplo conjunto de instrumentos (subsídios, financiamento, incentivos à cooperação, entre outros) de política de inovação em PEs (Dini; Stumpo, 2011; Ferraro, 2011).

Segundo Ferraro (2011, p. 464):

En los últimos años, los gobiernos han puesto especial interés en incentivar a las empresas de menor tamaño para que introduzcan innovación en sus procesos y productos. La incorporación de este tipo de políticas se sustenta en que ha comenzado a emerger, aunque muy incipientemente, una concepción de las pymes cada vez más como una pieza de la estructura productiva y cada vez menos como un "medio de subsistencia”. Todos los países, sin excepción, cuentan con iniciativas para impulsar las innovaciones. Las agencias buscan también transmitir a las pequeñas y medianas empresas la importancia del conocimiento como herramienta para mejorar la competitividad.

Nas subseções seguintes apresentam-se as linhas gerais desses instrumentos e alguns resultados analisados na literatura especializada.

\subsection{Subvenção econômica}

O tipo mais comum de subvenção econômica é o de concessão de recursos financeiros, mediante processos competitivos, a determinados segmentos empresariais (normalmente as PEs), e visando o desenvolvimento de setores e tecnologias específicas, em especial aquelas em que o retorno econômico é demorado. Diversos países desenvolvidos e em desenvolvimento, como Finlândia,

(4) A atuação do poder público no provimento de instrumentos de financiamento a empresas de pequeno porte é defendida inclusive na literatura mais convencional, que adota o conceito de "falhas de mercado". Os autores que se situam nessa corrente argumentam que o retorno social da inovação é maior que o retorno privado, o que justifica a atuação do governo. 
Coreia, Japão, Estados Unidos, Suécia e Reino Unido adotam esse tipo de instrumento de apoio à inovação em empresas de pequeno porte. (OECD, 2010).

Um dos programas mais antigos e conhecidos é o Small Business Innovation Research (SBIR), implementado no âmbito do Small Business Innovation Development Act (1982) nos Estados Unidos. O SBIR tem como objetivo principal estimular as inovações tecnológicas nas pequenas empresas privadas (com menos de 500 empregados) e o surgimento de novas empresas de base tecnológica.

Lerner (1996) compara o desempenho de empresas contempladas pelo programa vis-à-vis empresas não contempladas por meio de resultados de evolução das vendas e do emprego. A principal conclusão da avaliação realizada é a de que "the SBIR awardees enjoyed substantially greater employment and sales growth, but these effects were confined to firms in areas that attracted significant venture financing." (Lerner, 1996, p. 22). Portanto, além de realçar os resultados positivos alcançados pelas empresas beneficiadas pelos grants, verificou-se também o efeito da localização geográfica, com uma concentração dos recursos em áreas onde há intensa atividade de pesquisa e ambiente de forte empreendedorismo. Há ainda outras conclusões importantes do estudo, como a de que mesmo desconsiderando a importância dos recursos financeiros do Programa, o sinal dado pela aprovação do recurso pelo órgão responsável qualifica a inovação em pauta, aspecto assinalado pelas empresas que tiveram seus projetos aprovados.

Este aspecto de programas desta natureza é o foco da análise empreendida por Meuleman e De Maeseneire (2012) sobre PEs apoiadas pelo "IWT-Flanders' SME Innovation Program”, implementado no início dos anos 1990 na região de Flandres (Bélgica). Os autores demonstram que a obtenção de recursos para P\&D provoca um efeito de certificação positiva que facilita o acesso a financiamento privado, seja por meio de bancos ou de venture capital.

Ainda sobre o SBIR, Elston e Audretsch (2009) empreendem um estudo com vistas a identificar quais os principais fatores determinantes na decisão de abrir uma empresa. Dentre as variáveis observadas, os empréstimos e subvenção obtidos por meio do SBIR aparecem como a principal fonte de fundos para as startups, em detrimento de outros fatores analisados, como o capital pessoal do empreendedor.

Outra linha de análise encontra-se no estudo de Salles Filho et al. (2011), que realizam uma comparação entre os resultados do SBIR com os encontrados para o Pipe (Programa de Apoio à Inovação em Pequenas Empresas), programa implementado pela Fapesp (Fundação de Apoio à Pesquisa em São Paulo). A despeito de diferenças no ambiente institucional no qual os programas são implementados, os resultados mostram semelhanças importantes, em termos de sua capacidade de estimular a geração de novos produtos e processos nas empresas alvo, as pequenas empresas de base tecnológica. 
Dados da OECD para o início dos anos 2000 mostram que Estados Unidos, França e Reino Unido são os países que mais dedicam recursos públicos para subvenção econômica, embora todos os países considerados contemplem em alguma medida esta modalidade de apoio. O que muda entre os países é o percentual de recursos dedicado a cada tipo de apoio, levando-se em conta a divisão entre subvenção e incentivos fiscais (Iedi, 2010).

\subsection{Incentivos fiscais}

Os incentivos fiscais crescem em importância no apoio à inovação. Segundo recente documento da OECD (2010:103), "direct public funding through grants, subsidies and loans remains the most frequent form of support to business $R \& D$, with competitive and merit based grant programmes having gained ground. However tax relief for $R \& D$ continues to complement more direct measures in many countries."

Atualmente são 22 os países da OECD que preveem algum tipo de incentivo físcal à inovação, contra 12 países em 1995 e 18 em 1998. Em parte desses países, estabelecem-se diferenças entre grandes e pequenas empresas, como Noruega, Reino Unido, Japão, Canadá, Holanda, Itália e Bélgica (OECD, 2010). Especialmente no caso da União Europeia, são poucos os países que estabelecem diferenças entre empresas em relação ao porte, em função das normativas do Tratado da União Europeia, que dificultam determinados tratamentos fiscais. Entretanto, reconhece-se a necessidade de conceder tratamento diferenciado às jovens empresas inovadoras (COM, 2006).

A Tabela 1 indica os tratamentos fiscais para P\&D em alguns países da OECD e para o Brasil. Pode-se verificar que em muitos países não há distinção entre os incentivos fiscais para atividades de $\mathrm{P} \& \mathrm{D}$ em relação ao porte. No caso brasileiro, os incentivos fiscais (Lei do Bem e Lei de Informática) são dirigidos igualmente às pequenas, médias e grandes empresas. Os países que fornecem tratamento diferenciado por porte são Canadá, Coreia do Sul e Reino Unido.

O caso do Reino Unido merece destaque por se tratar de uma experiência de incentivo fiscal à P\&D exclusivo para pequenas e médias empresas. Em 2000, quando o programa foi constituído, o sistema de incentivos fiscais era direcionado a estimular atividades de inovação em pequenas e médias empresas. Após dois anos de exercício, em 2002, o programa de incentivos passou a contemplar também grandes empresas. Em 2004, totalizaram mais de 5.300 empresas participantes, sendo cerca de 4.300 pequenas e médias e 1.000 grandes empresas. Os incentivos fiscais baseiam-se nas deduções dos impostos sobre $125 \%$ dos gastos em P\&D elegíveis ou sobre $150 \%$ para pequenas e médias empresas, sendo que para cada $£ 1 \mathrm{~m}$ 
gasta em P\&D a empresa pode deduzir $£ 1,5 \mathrm{~m}$ do lucro do imposto a ser cobrado (UK, 2005).

Tabela 1

Incentivo Fiscal ao Gasto de P\&D Privado

(Incentivo para cada US\$ 1 gasto em P\&D) - 2008

\begin{tabular}{|c|c|c|}
\hline País & $\begin{array}{c}\text { Pequenas e Médias } \\
\text { Empresas }\end{array}$ & Grandes Empresas \\
\hline França & 0,425 & 0,425 \\
\hline Espanha & 0,349 & 0,349 \\
\hline Brasil (1) & 0,312 & 0,312 \\
\hline Portugal & 0,281 & 0,281 \\
\hline Índia & 0,269 & 0,269 \\
\hline Brasil (2) $^{(2)}$ & 0,254 & 0,254 \\
\hline Canadá & 0,326 & 0,180 \\
\hline Coreia do Sul & 0,158 & 0,180 \\
\hline África do Sul & 0,163 & 0,163 \\
\hline China & 0,138 & 0,138 \\
\hline Itália & 0,117 & 0,117 \\
\hline Austrália & 0,117 & 0,117 \\
\hline Japão & 0,159 & 0,159 \\
\hline Reino Unido & 0,179 & 0,105 \\
\hline 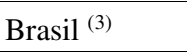 & 0,102 & 0,102 \\
\hline EUA & 0,066 & 0,066 \\
\hline
\end{tabular}

Obs: (1) dados de 2008 com a Lei de Informática; (2) dados segundo publicação da OCDE; (3) dados de 2008 sem a renúncia fiscal da Lei de Informática; (4) Mantevese aqui para o Brasil o mesmo critério da OCDE de que quando não há diferença formal de incentivos para PME estes são contabilizados como idênticos aos das grandes empresas.

Fonte: Warda (2009). Extraído de Iedi (2010).

O grande uso dos incentivos fiscais como instrumento de política de inovação no mundo culminou em uma ampla discussão internacional sobre sua capacidade de estimular as empresas a realizarem atividades de P\&D independentemente do seu porte. Muitos estudos empíricos testam a efetividade desse instrumento no que se refere à decisão de gasto em $\mathrm{P} \& \mathrm{D}$ das empresas, uma vez que a discussão da sua efetividade está em pauta por autores como Hall e Van Reenen (2000), Griffith et al. (2000) e Bloom et al. (2002). Um exemplo importante analisado na literatura é o caso do Canadá, onde o programa de incentivos fiscais promoveu um aumento de US\$1,38 nos gastos em P\&D a cada US\$1,00 de renúncia fiscal. Mais que isso, os resultados positivos dos incentivos fiscais também podem 
ser visualizados pelo aumento no número de novos produtos e pelo aumento nas vendas das empresas (Czarnitzki et al., 2004).

\subsection{Estímulo às redes de pequenas empresas}

O estímulo à constituição e desenvolvimento de redes de PEs, ou aquelas em que estas empresas tenham participação destacada, apresenta-se como elemento de crescente importância nas agendas atuais de política industrial (OECD, 1999; 2007). Embora tais redes apresentem formatos distintos e diversas nomenclaturas - distritos industriais, clusters, arranjos produtivos, sistemas localizados, milliers inovativos, polos tecnológicos, dentre outros -, o princípio que orienta as políticas a elas voltadas, em geral, é o do fomento às interações de diversos tipos e entre distintos agentes, com vistas ao desenvolvimento da produção e inovação. A constatação, em diferentes programas de pesquisa, de que a atuação em rede pode propiciar a superação, ao menos em parte, das debilidades estruturais que caracterizam o segmento das PEs, forma a base na qual os programas de apoio atuais foram forjados. Nestes programas, a consideração do território e dos ativos que lhe são específicos implica em apoiar a constituição e/ou o fortalecimento de interações entre empresas concorrentes e com empresas clientes e fornecedoras, com universidades e centros de pesquisa ou tecnológicos, além de outros agentes, como sindicatos e associações de classe, de forma a contribuir na geração do conhecimento necessário à introdução de inovações.

Os instrumentos voltados ao estímulo de redes de empresas têm apresentado grande diversidade, destacando-se os financiamentos a projetos conjuntos e à constituição e/ou aprimoramento de organizações dedicadas ao desenvolvimento produtivo/tecnológico das empresas da região em questão (OECD, 2007). São inúmeros os casos de constituição de incubadoras de empresas e parques tecnológicos, experiência que se tornou um dos pilares da política industrial francesa e alemã, por exemplo. Também pode ser citado o caso da constituição de centros tecnológicos especializados voltados ao desenvolvimento e difusão de tecnologias para as empresas de determinados setores industriais, caso da política industrial espanhola.

Embora tenha crescido muito a literatura que analisa as aglomerações de empresas, as pesquisas sobre os resultados do apoio público são ainda escassas em virtude, principalmente, de dificuldades metodológicas. Considerando-se que as redes, aglomeradas espacialmente ou não, apresentam singularidades determinadas pelo seu processo histórico de desenvolvimento, resultados em termos de performance são muito díspares.

Ademais, o reconhecimento de que as externalidades ligadas ao ambiente local são essenciais para a competitividade das empresas em aglomerações coloca o 
problema de como avaliar os efeitos oriundos de externalidades não intencionais, em relação aos efeitos que se originam de ações deliberadamente instituídas com vistas ao seu desenvolvimento 5 .

\subsection{Estímulo à formação de venture capital (VC)}

Pesquisas que mostram o papel positivo deste tipo de capital para a formação e desenvolvimento de empresas de base tecnológica que apresentam grande potencial de crescimento têm induzido governos a atuar de modo a fomentar o mercado de VC. Em geral, a atuação do setor público tem se direcionado para prover fundos que possam alavancar os investimentos dessas empresas ("fundos dos fundos") (OECD, 2010; COM, 2007).

Embora se apresente como uma opção importante para o financiamento de PEs, estudos recentes têm se dedicado a analisar as limitações que este tipo de financiamento apresenta. Hall (2002), em um amplo estudo sobre esta temática, argumenta que o financiamento por meio de VC tende a incidir sobre um número reduzido de setores (os que apresentam taxas de crescimento muito altas) e volumes de financiamento altos, excluindo grande parte de empresas de menor porte, em especial, startups. Ademais, a viabilidade deste tipo de investimento requer a presença de mercados de capitais apropriados (como a Nasdaq, nos Estados Unidos), a fim de propiciar estratégias de saída para os investidores.

Pode-se acrescentar que o apoio à constituição deste tipo de estrutura encontra mais limites no caso dos países em desenvolvimento, dado que os mercados de capitais são reduzidos até para as empresas de maior porte.

Além dos instrumentos citados, que têm sido os mais presentes em países desenvolvidos e em desenvolvimento, existem outros utilizados em maior ou menor grau, exemplo dos angels investors, innovation vouchers e compras públicas.

\subsection{Principais focos e problemas dos programas de apoio às pequenas empresas}

Alguns trabalhos de pesquisa têm se dedicado a analisar programas de apoio a PEs e seus principais problemas. Assim como algumas pesquisas anteriormente citadas, estes trabalhos tendem a focar suas análises sobre programas específicos, o que impede qualquer tipo de generalização. Entretanto, alguns aspectos destacados podem ser sumarizados, à guisa de referências para a análise do caso brasileiro.

- Os programas atuais de apoio são seletivos em relação ao segmento das PEs, na medida em que tendem a focalizar as empresas de base tecnológica,

(5) Problemas relacionados à avaliação das denominadas clusters policies estão sumarizados em OECD (2007) 
enquanto setores tradicionais, com significativa participação de empresas de pequeno porte, ficam excluídos dos principais programas (Kaufmann; Tödtling, 2002). O realce a este aspecto é importante considerando-se a inovação como um fenômeno horizontal, que perpassa todos os setores, inclusive aqueles classificados como low tech (Von Tunzelmann; Acha, 2006). O fato de que países em desenvolvimento tendem a ter suas estruturas produtivas com forte participação de setores tradicionais reforça a importância de se considerar os setores produtivos e suas especificidades em termos de atividades inovativas, que não se resumem a gastos em P\&D.

- Os programas tendem a definir instrumentos que se voltam, em grande medida, a aumentar os gastos em P\&D. Entretanto, para as empresas de pequeno porte, os gastos em $\mathrm{P} \& \mathrm{D}$ são uma das fontes de conhecimento para a inovação, nem sempre a mais importante. Estudos recentes, como o da OECD (2010), destacam a presença de um conjunto importante de empresas em vários países que são caracterizadas como innovative firms without $R \& D$.

- Os programas tendem a estimular gastos em P\&D para a obtenção de novos produtos e processos, mas são pouco efetivos na fase de comercialização das inovações (Kauffman; Tödtling, 2002). Em nível mais geral, pode-se destacar, como fazem Nawelaers e Wintjes, (s.d.), a ausência de instrumentos que sejam mais market orientation, ou seja, que estimulem a atividade inovativa até a sua fase final, a comercialização dos produtos.

Em suma, a maior parte dos países faz uso, atualmente, de uma ampla gama de instrumentos de apoio à atividade de inovação em PEs. Estima-se que cerca de $20 \%$ dos gastos de P\&D por parte de PMEs em países da OECD origina-se de recursos públicos, por meio de subvenção econômica ou renúncia fiscal, percentual que se situa em 14\% quando se trata de grandes empresas (Iedi, 2010).

De acordo com diversas pesquisas realizadas sobre a efetividade dos instrumentos mais comumente utilizados, ressalta-se a não existência de um mix ou best practice que seja recomendado a todos os casos. De acordo com os resultados de uma pesquisa realizada em 11 regiões europeias e diversos instrumentos utilizados no apoio à inovação em PMEs, a principal conclusão é que "(...) there is no 'one-size-fits-all' policy portfolio" (Nawelaers; Wintjes, s.d.).

Portanto, as diferenças nas estruturas produtivas e, com elas, as diferenças de inserção de PEs, em conjunto com a diversidade dos sistemas de financiamento ao setor produtivo, têm determinado a utilização de mixes diferenciados de instrumentos que, no geral, abarcam algum tipo de instrumento de financiamento direto e/ou subvenção econômica e algum tipo de incentivo fiscal. Estes e outros instrumentos serão analisados para o caso brasileiro. Antes, porém, apresenta-se um breve resumo do histórico e das mudanças recentes nas políticas públicas direcionadas às empresas de pequeno porte brasileiras. 


\section{A evolução das políticas públicas para pequenas empresas no Brasil}

Políticas públicas ${ }^{6}$ direcionadas às PMEs no Brasil iniciam-se na década de 1960, quando foi criado o Grupo Executivo de Assistência à Média e Pequena Empresa (GEAMPE), como instância do Banco Nacional de Desenvolvimento Econômico (BNDE). De acordo com o diagnóstico efetuado pelo Grupo, indicou-se ampliar o suporte financeiro às PMEs, o que levou à criação do Programa de Financiamento à Pequena e Média Empresa (Fipeme). O Fipeme foi pouco acionado pelas empresas no período e, na sequência, outras linhas de crédito voltadas ao capital de giro foram sendo criadas pelos bancos públicos.

As primeiras ações do poder público em prol do apoio financeiro às PMEs ocorreram em paralelo à implementação dos Planos de Desenvolvimento, que continham um claro direcionamento à formação de grandes conglomerados econômicos, o que tornava as ações direcionadas às PMEs desconectadas das políticas industriais. Destaque-se também que, neste primeiro momento, não havia nenhuma preocupação explícita com o tema do desenvolvimento tecnológico.

A criação da Financiadora de Estudos e Projetos (Finep), em 1967, destinouse a cobrir esta lacuna. A Finep, além de financiar o setor produtivo, laboratórios e centros de pesquisa nas universidades, responsabilizou-se pelo gerenciamento do Fundo Nacional de Desenvolvimento Científico e Tecnológico (FNDCT). Embora não se possa saber com precisão o volume de recursos destinados a PMEs, é reconhecido o papel que a agência teve na formação da infraestrutura de centros de pesquisa e universidades, que constituiu o ambiente que gerou, nos anos seguintes, muitas empresas de base tecnológica.

Por iniciativa conjunta da Finep, BNDE e ABDE (Associação dos Bancos de Desenvolvimento) foi criado, em 1972, o Centro Brasileiro de Assistência Gerencial à Pequena e Média Empresa (Cebrae), concebido para ser instituição pública atuante na difusão de novas técnicas de gestão para as PMEs e vinculado diretamente à Secretaria de Planejamento da Presidência da República.

Nos anos 1980, o destaque do apoio governamental às PEs foi a adoção de um marco legal diferenciado, expresso no Estatuto da Microempresa. Aprovado pelo Congresso Nacional em 1984, o Estatuto garantiu tratamento simplificado e favorecido às microempresas nos campos administrativo, tributário, previdenciário, trabalhista, creditício e de desenvolvimento empresarial. A Constituição promulgada em 1988 reforçou a diretriz em seu Artigo 179, que ratificou os benefícios obtidos com o Estatuto da Microempresa.

(6) As informações referentes às décadas de 1960 a 1980 baseiam-se em Suzigan e Souza (1990) e Suzigan (1992). O trabalho de Naretto et al. (2004) também foi utilizado como fonte de informações para esta seção. 
A década de 1990 inicia-se sob o signo de mudanças estruturais na economia brasileira. Com a definição da Política Industrial e de Comércio Exterior (PICE), mudase o foco das ações governamentais, que passam a priorizar políticas de cunho horizontal e uma ação estatal menos "interventora" e mais "reguladora" dos mercados. Consoante a esses objetivos, o governo altera o marco regulatório com a conversão do Cebrae em Serviço Brasileiro de Apoio à Micro e Pequena Empresa (Sebrae), em 1990. Muda-se a ação pública para a paraestatal no âmbito das PMEs, dado que o Sebrae passou a ser entidade civil de serviço social autônoma sem fins lucrativos e o governo tornou-se minoritário no Conselho Deliberativo. Com recursos da contribuição compulsória de $0,3 \%$ incidente sobre a folha de pagamentos das empresas, o Sebrae teve expressivo aumento de orçamento, o que implicou na ampliação do número de empresas atendidas, se comparado com o atendimento realizado à época do Cebrae.

Com os recursos ampliados, criam-se novos programas. Dentre os programas operados pelo Sebrae para apoio ao desenvolvimento tecnológico, incluíam-se o Programa de Apoio Tecnológico às Micro e Pequenas Empresas (Patme) e os de apoio a incubadoras e empresas de base tecnológica. O programa de maior abrangência foi o PATME, cujo objetivo principal era oferecer consultoria tecnológica individual às MPEs, para desenvolver projetos junto às instituições credenciadas (universidades, centros tecnológicos, instituições de pesquisa e escolas técnicas). O programa, já operado pela FINEP desde a década anterior, passou a ser desenvolvido conjuntamente com o Sebrae.

Nos anos 1990, o Ministério da Ciência e Tecnologia (MCT) também impulsionou os programas de apoio ao desenvolvimento tecnológico de empresas de pequeno porte, embora as ações não contivessem uma perspectiva de longo prazo e articulação com as demais ações ao setor produtivo. A principal razão repousa na ausência de um eixo norteador das ações, com o fim do governo Collor e o desmantelamento das proposições da Pice.

Neste período, o MCT lançou dois projetos de fomento à inovação tecnológica em MPEs por meio de financiamento não reembolsável: o Projeto Alfa, voltado ao custeio de estudos de viabilidade técnica e econômica, e o Projeto Ômega, que financiava projetos de pesquisa cooperativos. Os recursos eram destinados a instituições de pesquisa públicas ou privados sem fins lucrativos, ou a grupos de empresas que apresentassem contrapartida mínima de 50\% dos gastos. Em 1997, o Projeto Ômega foi incorporado ao Programa de Apoio ao Desenvolvimento Científico e Tecnológico (PADCT), com o nome de Projeto Cooperativo PréCompetitivo, guardando suas características originais.

Outras ações do MCT, por meio de suas agências de fomento, o CNPQ e a Finep, estiveram relacionadas à concessão de bolsas para contratação de pessoal 
qualificado por empresas com projetos de aprimoramento tecnológico, além de financiamento de projetos de pesquisa, difusão e informação tecnológica e apoio a incubadoras e parques tecnológicos.

Sobre as ações empreendidas neste período, Souza e Botelho (2001, p. 127) concluem que:

(...) houve um crescimento da importância desse segmento de empresas nas políticas para a indústria. Entretanto, não houve um tratamento adequado que gerasse uma inserção mais qualificada das PEs na estrutura industrial. Essa situação decorre, sobretudo, da ausência de uma política industrial que conduza ações para a indústria e trate as PEs como integrantes da estrutura industrial.

As políticas públicas voltadas às PMEs ampliam-se nos anos 2000, a partir da definição da Política Industrial, Tecnológica e de Comércio Exterior (Pitce) e de mudanças na legislação.

Dentre os objetivos prioritários da Pitce estavam o aumento da eficiência da estrutura produtiva, o aumento da capacidade de inovação das empresas brasileiras e a expansão das exportações. No documento da Pitce há uma referência explícita à necessidade de considerar a especificidade da inserção de PEs, assim como dos arranjos produtivos locais, na estrutura produtiva. Segundo avaliação de Cano e Silva (2010, p. 10):

no que se refere às empresas de menor porte, a Pitce apresentou um conjunto de instrumentos, entre eles: linhas de apoio à inovação da Finep e do BNDES, linhas de financiamento ao investimento do BNDES, linhas especiais para capital de giro do BNDES e da CEF, mudanças na legislação para MPEs e programas de apoio ao desenvolvimento organizacional e gerencial. Embora representem um avanço, tiveram pouco efeito prático nestes primeiros anos.

Sem constituir "um conjunto acabado e articulado" (Laplane; Sarti, 2006, p. 285), em virtude das dificuldades para reestruturar as instituições de planejamento, coordenação e fomento, a PITCE é substituída pela Política de Desenvolvimento Produtivo (PDP) em 2008.

Na PDP, a referência às PEs torna-se mais explícita, na medida em que dentre as quatro macrometas definidas para o período 2008-2010, uma se refere ao aumento do número de PMEs exportadoras. Este objetivo não foi alcançado, embora a ampliação da participação do Brasil no comércio internacional permaneça como uma das dez metas estabelecidas no Plano Brasil Maior (PBM), que substituiu a PDP para vigorar no período 2011-2014. Entretanto, não se estabeleceu uma meta específica para as empresas de pequeno porte, o que é um sinal inequívoco de que as fragilidades estruturais que caracterizam este segmento de empresas não puderam ser superadas pelas ações da política industrial na temporalidade desejada. 
Em relação à inovação, a principal meta da PDP era a de ampliar os gastos privados em P\&D, de $0,49 \%$ do PIB em 2008 para o patamar de $0,65 \%$ em 2010. Esta meta também não foi alcançada, embora tenha ocorrido crescimento no período, alcançando-se os patamares de 0,55\% e 0,57\% do PIB nos anos de 2010 e 2011, respectivamente, segundo dados preliminares do MCTI.

No PBM, que define como eixos principais das ações a inovação e a competitividade, novamente se atribui um importante papel às micro, pequenas e médias empresas (MPMEs). Neste Plano, a principal meta relativa às empresas de pequeno porte diz respeito ao aumento em 50\% de MPMEs inovadoras, de 37,1 mil em 2008 para 58 mil em 2014. Ademais, para o cumprimento da meta de promover o adensamento de diversas cadeias produtivas, expresso no aumento do Valor da Transformação Industrial em relação ao Valor Bruto da Produção Industrial, um conjunto de ações que pretendem melhorar sistemas de gestão, capacitação e atividade exportadora em setores específicos deverá ser direcionado às empresas de pequeno porte. Neste âmbito, o objetivo em relação às MPMEs é o de melhorar e/ou ampliar sua inserção em redes de fornecedores, em geral articuladas às grandes empresas das cadeias produtivas selecionadas.

Em todos estes Planos, a questão setorial é destacada. Na Pitce, os setores eleitos como prioritários foram os de Semicondutores, Softwares, Fármacos e Medicamentos e Bens de Capital. Na PDP, amplia-se a abrangência setorial, com a definição de 25 setores incluídos em três programas distintos, de acordo com o tipo de inserção na estrutura produtiva: "Programas mobilizadores em áreas estratégicas" (fármacos, software, etc.), "Programas para fortalecer a competitividade" (bens de capital, couro e calçados, etc.) e "Programas para consolidar e expandir liderança" (petróleo e gás, celulose e papel, etc.). Abrangência setorial semelhante aparece no PBM, que inclui dezenove setores em cinco Blocos de Sistemas Produtivos, a saber: Sistemas da Mecânica, Eletroeletrônica e Saúde; Sistemas produtivos intensivos em escala; Sistemas produtivos intensivos em trabalho; Sistemas produtivos do agronegócio; Comércio, logística e serviços.

A lógica que preside a atual política industrial, a combinação de elementos horizontais, notadamente o apoio à inovação e exportações, e verticais, com a contemplação de um amplo leque de setores, está em consonância com as experiências bem sucedidas de política industrial, como a japonesa e a coreana. Este aspecto tem sido avaliado positivamente em trabalhos como os de Cano e Silva (2010) e Carbinato e Corrêa (2008).

Portanto, desde 2004, com a PITCE, tenta-se colocar novamente a agenda de desenvolvimento industrial como foco das políticas públicas e como elemento central para o alcance de um novo estágio de desenvolvimento para a economia brasileira. 
Entretanto, diversos percalços para a implementação desta agenda estiveram presentes ao longo dos últimos anos.

Quando da implementação da PITCE, houve, de forma recorrente, contradições entre a política macroeconômica e a política industrial. $\mathrm{O}$ câmbio valorizado e os juros elevados foram obstáculos importantes à consecução da agenda industrial, conforme salientado por Laplane e Sarti (2006) e Cano e Silva (2010). Entretanto, a Pitce foi um elemento importante para a reconstrução desta agenda, após um período em que o aparelho estatal dedicado às ações para a indústria encontrava-se significativamente desmantelado em virtude da crise econômica desde o início dos anos 1980 e das ações de cunho liberalizante empreendidas nos anos $1990^{7}$.

No momento subsequente, com a definição da PDP em um contexto de crescimento econômico e de rearticulação do aparato político-institucional de apoio à indústria, diversas ações visando instrumentalizar os objetivos do Plano foram implementadas. O obstáculo mais importante para a consecução das principais metas da política industrial neste momento foi a deflagração da crise econômica internacional, em 2008, segundo avaliação da Agência Brasileira de Desenvolvimento Industrial (ABDI), órgão responsável pela implementação da política industrial.

Os efeitos negativos da crise internacional sobre o crescimento da economia brasileira permaneceram nos últimos anos, levando o governo a implementar um conjunto de medidas pontuais de apoio ao setor industrial que buscam, sobretudo, a sustentação do crescimento no curto prazo (especialmente as desonerações tributárias). Estas ações acabam, por vezes, a contradizer as metas da política industrial, voltadas para as mudanças de longo prazo ${ }^{8}$.

Em relação às mudanças na legislação ocorridas nos últimos anos, o destaque principal é a Lei de Inovação, aprovada em 2004, cujo objetivo é o de estimular a inovação por meio de novos instrumentos, como a subvenção econômica, e a eliminação de gargalos institucionais à cooperação público-privada.

A legislação sofre alterações ainda com a Lei do Bem, de 2005, que dispõe sobre incentivos fiscais a gastos de P\&D, e a Lei de Informática, criada em 1991 e modificada em 2001, que prevê a redução de IPI como contrapartida aos gastos em P\&D. A Lei do Bem apoiou 130 empresas em 2006, 299 empresas em 2007 e 441 empresas em 2008, representando um crescimento de $240 \%$ no período. Destaca-se também que o investimento em P\&D das empresas beneficiárias pela Lei do Bem se

(7) Suzigan e Furtado (2010) apresentam uma excelente análise dos percalços atuais da política industrial brasileira. Para os autores, no período em que a política industrial teve seu papel negligenciado nas políticas públicas brasileiras, houve o desmantelamento de importantes instituições voltadas ao desenvolvimento industrial, além de não se ter forjado uma institucionalidade que suporte os novos desafios impostos à política industrial no bojo do novo paradigma técnico-produtivo.

(8) Ver Schapiro (2014), para uma avaliação das principais dificuldades no processo de implementação da PBM. 
ampliou de 2,1 bilhões em 2006, para 8,1 bilhões em 2008 (MCT, 2010). Mesmo diante desse acentuado crescimento, a maior parte das empresas beneficiadas por esse instrumento são grandes empresas, pelo fato de serem lucrativas e por já realizarem previamente atividades de P\&D.

A partir da conjugação de mudanças na legislação, aumento orçamentário e pioneirismo na implantação de programas voltados à inovação tecnológica em empresas, a Finep instituiu, nos anos 2000, diversos programas direcionados ao financiamento à inovação em PEs, tanto com recursos reembolsáveis, quanto com recursos de subvenção econômica. Dentre os programas operados com recursos de subvenção econômica, se destacam o Prime (Primeira Empresa Inovadora), voltado a empresas nascentes; Subvenção Econômica; e o Pappe (Programa de Apoio à Pesquisa em Empresas), direcionado para micro e pequenas empresas e operado a partir das Fundações de Apoio a Pesquisas estaduais ${ }^{9}$.

Com recursos reembolsáveis, a Finep instituiu também novos programas nos anos 2000, que tentam contribuir para a melhoria das condições de financiamento das empresas nacionais. São exemplos o Programa Juro Zero, sem exigência de garantias reais e voltado a setores de tecnologia avançada, e o Projeto Inovar, com foco no desenvolvimento de fundos de capital de risco.

O maior direcionamento das políticas públicas para o apoio à inovação em PEs também ocorreu por parte do Banco Nacional de Desenvolvimento Econômico e Social (BNDES), que tradicionalmente destinou recursos às grandes empresas nacionais e aos projetos de infraestrutura. Por meio de um conjunto de novos instrumentos, o Banco tem conseguido aumentar de forma consistente os recursos destinados às PEs e à inovação. Dentre os programas atualmente em execução, destacam-se: Linha Capital Inovador (foco na empresa), Linha Inovação Produção e Linha Inovação Tecnológica (foco no projeto). Estas linhas, abrigadas no programa BNDES Finem, tiveram seus valores de referência alterados para que houvesse direcionamento à inovação tecnológica em PEs.

Outra iniciativa que merece destaque refere-se à articulação, pelo governo federal, do plano de desenvolvimento produtivo (Plano Brasil Maior) com a Estratégia Nacional de Ciência, Tecnologia e Inovação (ENCTI) 2012-2015, do Ministério da Ciência, Tecnologia e Inovação (MCTI). A Encti dá continuidade às ações do Plano de Ação em Ciência, Tecnologia e Inovação, conjunto de iniciativas voltadas à área de ciência e tecnologia que vigorou no período 2007-2010. As principais diretrizes da Encti baseiam-se na ampliação de recursos financeiros, na capacitação de recursos humanos, no fortalecimento da infraestrutura científica e

(9) Matos e Arroio (2011) mostram, por meio de dados do MCT, que os recursos de subvenção têm aumentado nos últimos anos, além de ter havido um direcionamento crescente para as micro e pequenas empresas, que obtiveram $63 \%$ do total dos recursos em 2006 e $81 \%$ em 2009. 
tecnológica, no enfoque sistêmico à ação de apoio do Estado e no adensamento tecnológico das cadeias produtivas (MCTI, 2012).

O conjunto de ações a serem implementadas presentes no âmbito da Encti amplia os esforços que vêm sendo implementados desde meados dos anos 2000, a partir de uma concepção sistêmica da inovação. Embora ainda não seja possível avaliar a efetividade das ações em andamento, o que diferencia a Estratégia atual, considerando-se as decisões e instrumentos já anunciados pelo MCTI, é o maior volume de recursos envolvidos; o caráter transversal das ações, que envolve recursos de praticamente todos os ministérios e de agências e bancos de fomento; e o foco em adensamento de cadeias produtivas, em consonância com as ações do PBM.

O direcionamento de esforços voltados a esta área desde meados dos anos 2000 já produziu resultados importantes, como o aumento do volume de gastos públicos e privados em C\&T (de 1,30\% do PIB em 2000, para 1,64\% em 2011, segundo dados preliminares do MCTI), o aumento do número de artigos científicos (de 24.171 em 2000 para 72.915 artigos em periódicos de circulação internacional em 2010) e o aumento do número de mestres e doutores (de 5.318 títulos de doutor em 2000 para 13.912 em 2012) (MCTI, 2014). Estes resultados permitiram melhorar o desempenho brasileiro em diversos rankings internacionais. Entretanto, quando se analisa os indicadores que captam os resultados de inovação, verifica-se que a distância que separa o Brasil de países avançados não sofreu alterações relevantes. São exemplos, a taxa de inovação, que avançou pouco na primeira década dos anos 2000 e diminuiu na versão mais recente da Pintec, situando-se no patamar de 35,7\% em 2011; o indicador de patentes; e os gastos privados em P\&D que, embora tenham crescido em termos absolutos e relativos, ainda estão muito distantes dos verificados em países desenvolvidos.

Em síntese, o conjunto de indicadores que captam a dimensão e qualidade do sistema de inovações indica a ocorrência de avanços importantes, mas ainda insuficientes para mudar a posição relativa do Brasil no cenário internacional ${ }^{10}$.

Em relação às empresas de pequeno porte, também houve mudanças importantes no aparato político-institucional de apoio à inovação. Estas se consubstanciam em um novo regime de incentivos fiscais (Lei do Bem), em novos programas de apoio financeiro (por meio da Finep e BNDES, principalmente) e em estímulos às parcerias entre empresas e outros agentes do sistema de inovações, em particular as universidades e centros de pesquisa (Finep, Sebrae e instituições de cunho estadual).

(10) A partir da utilização de bases de dados internacionais de artigos científicos, patentes e renda per capita para os anos 1990 a 2003, Albuquerque (2009, p. 56) conclui que “(...) tanto na produção científica e tecnológica como na renda per capita, o esforço realizado no país tem sido suficiente apenas para manter-se na mesma posição. O Brasil corre para ficar no mesmo lugar: eis o "efeito rainha vermelha"”. 
Tanto o fato de serem programas instituídos recentemente, como o seu direcionamento para as empresas de pequeno porte, torna importante a apreensão das características das empresas efetivamente contempladas, assim como dos resultados alcançados em termos de esforço e desempenho inovativo. Este é o tema da seção seguinte, que constitui o núcleo do presente artigo.

\section{Evidências empíricas para o caso brasileiro}

O objetivo dessa seção é desenvolver uma análise empírica sobre o perfil das empresas inovadoras que participaram de algum programa de incentivo à inovação, com ênfase nas empresas de pequeno porte. Para isso, são utilizados dados das últimas três edições (2003, 2005 e 2008) da Pesquisa de Inovação Tecnológica (Pintec), realizada pelo IBGE, que foram obtidos mediante uma tabulação especial elaborada exclusivamente para o presente trabalho.

A Pintec (2010) desagrega as políticas de inovação em incentivos fiscais, financiamento, bolsas de estudos e capital de risco. Fazem parte da categoria de incentivos fiscais, os incentivos fiscais para atividades de P\&D e inovação tecnológica (Lei n.8661 e Lei do Bem) e os incentivos fiscais dirigidos ao setor de Informática (Lei de Informática).

Dentre os programas de financiamento, a Pintec enfatiza programas em que a empresa busca financiamento a projetos de P\&D e à inovação tecnológica com e sem parceria com universidades ou institutos de pesquisa para atividades inovativas. Outro tipo de programa de apoio financeiro refere-se a programas de financiamento exclusivo para a compra de máquinas e equipamentos utilizados para inovar. Também são considerados os programas de subvenção econômica à $\mathrm{P} \& \mathrm{D}$ e à inserção de pesquisadores, assim como a utilização de bolsas oferecidas pelas fundações de amparo à pesquisa e pelo programa $\mathrm{RHAE} / \mathrm{CNPq}$ para pesquisadores em empresas. Por fim, a Pintec ressalta também a utilização do instrumento capital de risco como apoio do governo para a realização das atividades inovativas das empresas.

A amostra de empresas da Pintec (2005) é constituída de 59.993 empresas inovadoras ${ }^{11}$, sendo $5 \%$ (5.485 empresas) dessas empresas financiadas pelos programas públicos de apoio à inovação. Na Pintec (2007), das 67.704 empresas inovadoras entrevistadas, 9,2\% delas foram financiadas pelo governo (6.189 empresas), enquanto que na Pintec (2010), das 81.177 empresas inovadoras, $12 \%$ delas receberam suporte público (9.763 empresas).

(11) Por empresas inovadoras, nesse estudo, foram consideradas as empresas que realizaram no período analisado gastos com alguma atividade inovativa (gastos com P\&D interno, gastos com P\&D externo, gastos com máquinas e equipamentos, por exemplo). 
Nota-se que ainda é pequeno o percentual de empresas que receberam apoio do governo para inovação. Esse resultado corrobora as considerações apresentadas por Matos e Arroio (2011). Os referidos autores, com base em dados retirados da Pintec (2010), utilizam um conceito mais restrito para as empresas inovadoras (exclusivamente as empresas que implementaram inovação), e evidenciam que das 41.262 empresas inovadoras, somente $22,3 \%$ delas receberam suporte público para inovar.

Por outro lado, ainda que o percentual de empresas contempladas seja pequeno, vem ocorrendo um importante aumento na participação das empresas em programas de apoio, considerando as informações obtidas pelas três edições da Pintec, apresentadas na Tabela 2. Esse aumento da participação das empresas nos programas de apoio à inovação está relacionado à ampliação dos recursos e do número de instrumentos oferecidos pelo governo, como já apresentado na Seção 2.

A Tabela 2 também evidencia o aumento da participação das empresas de pequeno porte nos programas de apoio à inovação. Segundo dados da Pintec (2010), observa-se que, do total de 72.681 pequenas empresas, 11,51\% delas foram contempladas com programas públicos de apoio à inovação. Essa participação aumenta ao se considerar as grandes empresas, sendo que de 1.685 delas, 28,55\% foram contempladas por suporte público à inovação (481 empresas).

De acordo com a Pintec (2005), das 5.485 empresas beneficiadas, 82\% delas são de pequeno porte. Observa-se que esse quadro se repete nas outras edições da pesquisa, alcançando, na Pintec (2010), 86\% das pequenas empresas inovadoras beneficiadas. Esse resultado indica uma grande e crescente participação das pequenas empresas como beneficiárias do suporte público.

Diante do aumento da participação das empresas de pequeno porte nos programas públicos, é importante analisar o comportamento das empresas beneficiadas e não beneficiadas pelos programas, utilizando-se de três conjuntos de indicadores. O primeiro conjunto de indicadores caracteriza as empresas quanto ao número de pessoal ocupado, receita líquida de vendas, origem de capital e participação em grupo empresarial. O segundo conjunto de variáveis engloba medidas de esforço inovativo, não se restringindo somente a esforços de P\&D, incluindo gastos com atividades inovativas, proporção do pessoal ocupado com $3^{\circ}$ grau, P\&D contínuo e participação em arranjos cooperativos e incubadoras. A terceira dimensão de análise apresenta um conjunto de indicadores de resultado, que também inclui, além do resultado formal como patentes, indicadores de produtividade do trabalho, proteção estratégica, inovação de produto, de processo e organizacional. 
Tabela 2

Número de empresas inovadoras beneficiárias e não beneficiárias dos Programas de Apoio à Inovação - Pintec 2003, 2005 e 2008 por Porte da Empresa

\begin{tabular}{l|c|c|c|c|c|c|c|c|c|c|c|c}
\hline & \multicolumn{4}{|c|}{2003} & \multicolumn{3}{c|}{2005} & \multicolumn{3}{c}{2008} \\
\hline $\begin{array}{l}\text { Porte da } \\
\text { empresa }(*)\end{array}$ & Benef. & $\%$ & $\begin{array}{c}\text { Não } \\
\text { Benef. }\end{array}$ & $\%$ & Benef. & $\%$ & $\begin{array}{c}\text { Não } \\
\text { Benef. }\end{array}$ & $\%$ & $\begin{array}{c}\text { Bene } \\
\text { f. }\end{array}$ & $\begin{array}{c}\text { Não } \\
\text { Benef. }\end{array}$ & $\%$ \\
\hline Pequenas & 4.510 & 82 & 48.718 & 89 & 4.644 & 75 & 54.719 & 90 & 8.367 & 86 & 64.314 & 90 \\
\hline Médias & 630 & 11 & 4.821 & 9 & 1.019 & 16 & 5.194 & 9 & 914 & 9 & 5.897 & 8 \\
\hline Grandes & 345 & 6 & 909 & 2 & 526 & 8 & 972 & 2 & 481 & 5 & 1.204 & 2 \\
\hline Amostra Total & 5.485 & 100 & 54.448 & 100 & 6.189 & 100 & 60.885 & 100 & 9.763 & 100 & 71.414 & 100 \\
\hline
\end{tabular}

(*) Pequenas empresas - 0 a 99 empregados; Médias empresas - de 100 a 499 empregados; Grandes empresas - acima de 500 empregados.

Fonte: Pintec (2005, 2007 e 2010).

A Tabela 3 apresenta os referidos conjuntos de indicadores para as empresas de pequeno, médio e grande porte, beneficiadas e não beneficiadas, divididas por programas de incentivo fiscal e de incentivo financeiro.

A primeira constatação importante é que, de maneira geral, as empresas beneficiadas, independente do porte, concentram um número mais elevado de pessoal ocupado, um percentual maior de empresas estrangeiras e de empresas participantes em grupo empresarial. Ressalta-se ainda que as empresas beneficiadas também apresentam receita líquida de vendas superior, em média, ao valor das empresas não beneficiadas.

Quanto aos indicadores de esforço inovativo, verifica-se a existência de um padrão. As empresas beneficiadas, independente do porte, apresentam indicadores de esforço inovativo (gastos em $\mathrm{P} \& \mathrm{D}$, gastos em atividades inovativas, proporção de funcionários com $3^{\circ}$ grau completo, $\mathrm{P} \& \mathrm{D}$ contínuo) superiores às empresas não beneficiadas. Nessa mesma direção, os indicadores de participação em incubadoras e em arranjos cooperativos mostram uma participação superior das empresas beneficiadas em relação às não beneficiadas.

Quanto aos indicadores de desempenho inovativo, essa superioridade permanece, dado que as empresas de pequeno, médio e grande porte que receberam suporte do governo apresentam produtividade do trabalho e índice de patenteamento superiores ao grupo das não beneficiadas. $O$ indicador de inovação organizacional apresenta um comportamento distinto, pois as empresas não beneficiadas realizam com maior frequência esse tipo de inovação em relação às empresas beneficiadas. Uma possível justificativa para esse comportamento está no fato de que grande parte desses programas de apoio à inovação não tem o objetivo de estimular a implementação de novas técnicas de gestão para melhorar rotinas e práticas de trabalho e novos métodos de organização do trabalho. 
Ao se considerar os tipos de programas de apoio à inovação (incentivos fiscais e incentivos financeiros), nota-se que o número de empresas de pequeno e médio porte beneficiadas pelos incentivos fiscais é menor em relação ao número de empresas beneficiadas pelos incentivos financeiros. Verifica-se, assim, que os incentivos financeiros atendem a uma gama maior de empresas de pequeno e médio porte, estando, as grandes empresas mais concentradas em programas de incentivo fiscal.

Ainda considerando os tipos de programa de apoio à inovação, observam-se diferenças entre o grupo de empresas que receberam suporte do governo pelos incentivos fiscais em relação ao grupo que recebeu incentivos financeiros. As empresas que receberam incentivo fiscal apresentam indicadores superiores tanto de esforço inovativo (gastos em P\&D e gastos em atividades inovativas) quanto de resultado (produtividade do trabalho). Esse resultado corrobora as evidências apresentadas na literatura internacional, que considera que o perfil das empresas que se beneficiam de incentivos fiscais e incentivos financeiros é distinto. As empresas beneficiadas por incentivos fiscais destacam-se por apresentarem melhores indicadores de esforço inovativo pelo fato de realizarem o esforço de inovação exante e obterem o benefício posteriormente. (David et al., 2000; Avellar; Alves, 2008).

Dentre as empresas de pequeno porte, as empresas beneficiadas pelos incentivos fiscais e financeiros apresentam perfis diferentes. Essa diferença de perfis corrobora as evidências de heterogeneidade no segmento das pequenas empresas, como já destacado na seção 1. As empresas beneficiadas pelos incentivos físcais apresentam alguns indicadores de esforço inovativo mais convencionalmente tratados na literatura, como gastos em $\mathrm{P} \& \mathrm{D}$, gastos em atividades inovativas, proporção de funcionários com $3^{\circ}$ grau completo, superiores ao grupo das pequenas empresas beneficiadas pelos incentivos financeiros. Por outro lado, dentre as empresas de pequeno porte, as que receberam incentivos financeiros apresentam elevados indicadores de esforço inovativo, tais como maior participação em arranjos cooperativos, participação em incubadoras, realização de $\mathrm{P} \& \mathrm{D}$ de forma contínua. Destaca-se, dentre esses indicadores, que 74,3\% das pequenas empresas beneficiadas pelos incentivos financeiros participaram de arranjos cooperativos. Esse resultado ilustra a efetividade do suporte público na realização de parcerias e formação de redes de empresas.

Sobre os indicadores de resultado, tais como patentes, proteção estratégica e proteção formal, observa-se que no conjunto de empresas beneficiadas pelos incentivos financeiros, as pequenas empresas apresentam indicadores de patenteamento $(73,17 \%)$ e de proteção estratégica $(73,05 \%)$ mais elevados que as empresas de médio e grande porte, beneficiadas por esses incentivos. 
Tabela 3

Características das Pequenas, Médias e Grandes Empresas Beneficiárias

(por Tipo de Programas de Apoio à Inovação) e Não Beneficiárias - Pintec 2008 (média, desvio padrão e \%)

\begin{tabular}{|c|c|c|c|c|c|c|c|c|c|}
\hline \multirow[b]{3}{*}{ Variáveis } & \multicolumn{3}{|c|}{ Pequenas } & \multicolumn{3}{|c|}{ Médias } & \multicolumn{3}{|c|}{ Grandes } \\
\hline & \multicolumn{2}{|c|}{ Beneficiárias } & \multirow{2}{*}{ Não Benef. } & \multicolumn{2}{|c|}{ Beneficiárias } & \multirow{2}{*}{ Não Benef. } & \multicolumn{2}{|c|}{ Beneficiárias } & \multirow{2}{*}{$\begin{array}{l}\text { Não } \\
\text { Benef. }\end{array}$} \\
\hline & Fiscal & Financ. & & Fiscal & Financ. & & Fiscal & Financ. & \\
\hline \multicolumn{10}{|c|}{ Características das Empresas } \\
\hline Pessoal Ocupado (unidade) & $\begin{array}{l}24,73 \\
(2,04)\end{array}$ & $\begin{array}{l}29,69 \\
(0,96)\end{array}$ & $\begin{array}{l}27,93 \\
(0,36) \\
\end{array}$ & $\begin{array}{l}285,58 \\
(14,52)\end{array}$ & $\begin{array}{l}219,6 \\
(6,92)\end{array}$ & $\begin{array}{l}201,23 \\
(2,12)\end{array}$ & $\begin{array}{c}3469,74 \\
(342,1)\end{array}$ & $\begin{array}{l}2555,78 \\
(332,81) \\
\end{array}$ & $\begin{array}{c}1536,92 \\
(72,71)\end{array}$ \\
\hline Receita Líquida de Vendas (R\$1000) & $\begin{array}{c}4905 \\
(1284)\end{array}$ & $\begin{array}{l}3131 \\
(300)\end{array}$ & $\begin{array}{l}2792 \\
(130)\end{array}$ & $\begin{array}{l}119860 \\
(20808)\end{array}$ & $\begin{array}{l}60511 \\
(9043)\end{array}$ & $\begin{array}{l}42601 \\
(1342)\end{array}$ & $\begin{array}{l}2605655 \\
(733930)\end{array}$ & $\begin{array}{l}1630021 \\
(747410)\end{array}$ & $\begin{array}{l}467130 \\
(44533) \\
\end{array}$ \\
\hline Multinacional (\% estrangeiras) & 19,79 & 28,67 & 1,79 & 29,81 & 32,71 & 11,83 & 72,44 & 28,85 & 28,37 \\
\hline Grupo (\%) & 13,27 & 40,18 & 6,71 & 24,64 & 50,82 & 24,12 & 56,20 & 42,62 & 47,77 \\
\hline \multicolumn{10}{|c|}{ Indicadores de Esforço Inovativo } \\
\hline Gastos com P\&D (R\$1000) & $\begin{array}{c}257,14 \\
(260,77) \\
\end{array}$ & $\begin{array}{c}59,67 \\
(33,92) \\
\end{array}$ & $\begin{array}{c}7,13 \\
(1,11)\end{array}$ & $\begin{array}{l}4122,81 \\
(813,14) \\
\end{array}$ & $\begin{array}{c}1104,63 \\
(252,51) \\
\end{array}$ & $\begin{array}{l}71,68 \\
(9,39) \\
\end{array}$ & $\begin{array}{c}42480,1 \\
(11194,3) \\
\end{array}$ & $\begin{array}{c}31239,1 \\
(11417,4)\end{array}$ & $\begin{array}{c}2390,9 \\
(799,39) \\
\end{array}$ \\
\hline Gastos com Atividades Inovativas ( $\mathrm{R} \$ 1000)$ & $\begin{array}{c}506,04 \\
(268,96)\end{array}$ & $\begin{array}{c}477,73 \\
(151,51)\end{array}$ & $\begin{array}{c}83,46 \\
(11,36)\end{array}$ & $\begin{array}{c}6842,02 \\
(1076,38)\end{array}$ & $\begin{array}{l}5765,61 \\
(1301,2)\end{array}$ & $\begin{array}{c}726,9 \\
(77,52)\end{array}$ & $\begin{array}{c}76063,06 \\
(14298,7)\end{array}$ & $\begin{array}{l}62223,6 \\
(14307)\end{array}$ & $\begin{array}{l}8888,22 \\
(1431,7)\end{array}$ \\
\hline $\begin{array}{l}\text { Proporção de Funcionários com } 3^{\circ} \text { Grau } \\
\text { (unidade) }\end{array}$ & $\begin{array}{c}7,38 \\
(3,29) \\
\end{array}$ & $\begin{array}{c}1,87 \\
(0,62) \\
\end{array}$ & $\begin{array}{c}0,31 \\
(0,04)\end{array}$ & $\begin{array}{c}3,57 \\
(0,62)\end{array}$ & $\begin{array}{c}0,82 \\
(0,15) \\
\end{array}$ & $\begin{array}{l}0,39 \\
(0,2)\end{array}$ & $\begin{array}{c}1,87 \\
(0,24)\end{array}$ & $\begin{array}{c}1,08 \\
(0,15) \\
\end{array}$ & $\begin{array}{l}0,45 \\
(0,2) \\
\end{array}$ \\
\hline Incubadora $(\%)$ & 38,53 & 60,21 & 1,38 & 30,44 & 58,31 & 1,42 & 73,86 & 45,75 & 0,92 \\
\hline P\&D Contínuo (\%) & 14,17 & 72,54 & 2,64 & 42,58 & 55,84 & 6,75 & 66,94 & 42,75 & 24,91 \\
\hline Arranjo Cooperativo (\%) & 7,58 & 74,29 & 3,53 & 25,67 & 63,73 & 6,41 & 58,06 & 52,42 & 19,36 \\
\hline \multicolumn{10}{|c|}{ Indicadores de Resultado } \\
\hline Produtividade do Trabalho ( $\mathrm{R} \$ 1000)$ & $\begin{array}{c}71,26 \\
(23,75)\end{array}$ & $\begin{array}{l}48,17 \\
(6,47) \\
\end{array}$ & $\begin{array}{l}37,43 \\
(0,99) \\
\end{array}$ & $\begin{array}{l}138,43 \\
(15,65)\end{array}$ & $\begin{array}{l}81,26 \\
(5,43) \\
\end{array}$ & $\begin{array}{l}70,98 \\
(2,03) \\
\end{array}$ & $\begin{array}{l}270,67 \\
(37,34)\end{array}$ & $\begin{array}{l}134,88 \\
(13,15)\end{array}$ & $\begin{array}{c}224,09 \\
(120,58) \\
\end{array}$ \\
\hline Inovação de Produto (\%) & 13,66 & 58,78 & 27,49 & 19,50 & 64,93 & 29,68 & 54,74 & 46,46 & 49,85 \\
\hline Inovação de Processo (\%) & 9,58 & 72,22 & 35,88 & 14,63 & 67,94 & 38,37 & 48,97 & 49,35 & 58,68 \\
\hline Patente $(\%)$ & 11,13 & 73,17 & 2,09 & 28,33 & 66,99 & 6,83 & 66,50 & 42,12 & 19,13 \\
\hline Proteção Formal (\%) & 11,22 & 70,31 & 12,09 & 19,22 & 66,16 & 20,26 & 56,28 & 44,86 & 38,36 \\
\hline Proteção Estratégica (\%) & 6,08 & 73,05 & 4,84 & 20,46 & 64,76 & 10,41 & 51,86 & 48,92 & 23,87 \\
\hline Inovação Organizacional (\%) & 9,28 & 65,38 & 90,07 & 15,39 & 65,11 & 95,13 & 49,02 & 48,07 & 94,48 \\
\hline Número Empresas (unidades) & 801 & 5.564 & 64.314 & 140 & 595 & 5.897 & 235 & 229 & 1.204 \\
\hline
\end{tabular}

Fonte: Pintec (2010). 
A Tabela 4 apresenta a distribuição das empresas beneficiárias para a amostra da Pintec 2008 nos diversos programas de apoio à inovação implementados em relação ao porte (pequenas, médias e grandes empresas). As empresas de pequeno porte participam predominantemente de programas de financiamento para aquisição de máquinas e equipamentos (5.059 empresas) e em incentivo fiscal à informática (634 empresas). Essa evidência corrobora os resultados apresentados por Botelho et al. (2011) que mostram que, no caso das empresas de pequeno porte de diversos países analisados, o tipo de esforço inovativo predominante é a aquisição de máquinas e equipamentos com conteúdo tecnológico inovador, indicando o foco das referidas empresas em inovação incremental.

As médias empresas apresentam uma participação expressivamente menor às pequenas empresas, sendo que a maior participação concentra-se em programas de financiamento para aquisição de máquinas e equipamentos (524 empresas) e incentivo fiscal à $\mathrm{P} \& \mathrm{D}$ (85 empresas). As grandes empresas predominantemente utilizam-se do programa de incentivo fiscal à $\mathrm{P} \& \mathrm{D}$, sendo que das 506 empresas beneficiadas, $42 \%$ delas fazem uso desse instrumento. A grande utilização desse instrumento pelas empresas de grande porte se deve ao fato de serem empresas lucrativas, por realizarem o esforço inovativo ex-ante e se beneficiarem do suporte do governo posteriormente, quando do pagamento do imposto sobre lucro líquido.

Tabela 4

Número de empresas beneficiárias por tipo de Programas de Apoio à Inovação -2008 por porte da empresa

\begin{tabular}{c|c|c|c|c|c|c|c|c|c|c}
\hline Porte da & $\begin{array}{c}\text { Incentivo } \\
\text { Fiscal } \\
\text { P\&D }\end{array}$ & $\%$ & $\begin{array}{c}\text { Fiscal } \\
\text { Informática }\end{array}$ & $\%$ & $\begin{array}{c}\text { Participação } \\
\text { em projetos } \\
\text { com } \\
\text { parceria }\end{array}$ & $\%$ & $\begin{array}{c}\text { Financ, } \\
\text { Máquinas }\end{array}$ & $\%$ & Bolsas & $\%$ \\
\hline Pequenas & 209 & 41 & 634 & 84 & 354 & 74 & 5.059 & 88 & 204 & 79 \\
\hline Médias & 85 & 17 & 74 & 10 & 61 & 13 & 524 & 9 & 31 & 12 \\
\hline Grandes & 213 & 42 & 46 & 6 & 62 & 13 & 153 & 3 & 23 & 9 \\
\hline $\begin{array}{c}\text { Amostra } \\
\text { Total }\end{array}$ & 506 & 100 & 754 & 100 & 477 & 100 & 5.736 & 100 & 258 & 100 \\
\hline
\end{tabular}

Fonte: Pintec (2010).

A Tabela 4 também exalta a grande participação das pequenas empresas em instrumentos de apoio como participação em projetos com parceria, bolsas de apoio a pesquisadores e participação em programas de capital de risco $(74 \%, 79 \%$ e $82 \%$, respectivamente, das empresas beneficiadas). Esses dados ilustram não apenas o aumento da participação das empresas de pequeno porte nos programas públicos, mas também que a diversidade de programas está atingindo empresas inovadoras desse porte. 
$\mathrm{Na}$ Tabela 5 podem ser observadas as características das pequenas empresas participantes dos seis programas de apoio do governo à inovação, presentes na Pintec e destacados nesse estudo.

As pequenas empresas que receberam incentivo fiscal apresentam, em média, receita líquida, gastos com $\mathrm{P} \& \mathrm{D}$, gastos com atividades inovativas e proporção dos funcionários com $3^{\circ}$ grau superiores à média desses indicadores de empresas beneficiadas por outros programas. Destaca-se que das empresas que participaram dos incentivos fiscais pela Lei de Informática, 20\% delas são multinacionais, apresentam elevada produtividade do trabalho e alto percentual, em média, de inovação de produto. No conjunto de empresas beneficiadas pelo incentivo fiscal à $\mathrm{P} \& \mathrm{D}$ as empresas apresentam, em média, o maior gasto em $\mathrm{P} \& \mathrm{D}$, o maior gasto em atividades inovativas e o maior percentual de empresas participantes de grupo $(12,16 \%)$.

O financiamento para aquisição de máquinas e equipamentos, por sua vez, é o programa de apoio à inovação mais utilizado pelas empresas de pequeno porte (5.059 empresas). Dentre as principais características das empresas que utilizam esse instrumento destacam-se o elevado percentual de empresas que participam de grupo, de arranjos cooperativos, de incubadoras e que realizam P\&D de maneira contínua.

Tabela 5

Características das pequenas empresas beneficiárias (de 10 a 99 funcionários) por Tipo de Programas de Apoio à Inovação - Pintec 2008 (média, desvio padrão e \%)

\begin{tabular}{|c|c|c|c|c|c|c|}
\hline Variáveis & $\begin{array}{c}\text { Incentivo } \\
\text { Fiscal } \\
\text { P\&D } \\
\end{array}$ & $\begin{array}{c}\text { Incentivo } \\
\text { Fiscal } \\
\text { Informática } \\
\end{array}$ & $\begin{array}{l}\text { Participação } \\
\text { em projetos } \\
\text { com parceria }\end{array}$ & $\begin{array}{l}\text { Financ, } \\
\text { Máquinas }\end{array}$ & Bolsas & $\begin{array}{l}\text { Capital } \\
\text { de Risco }\end{array}$ \\
\hline \multicolumn{7}{|c|}{ Características das Empresas } \\
\hline $\begin{array}{l}\text { Pessoal Ocupado } \\
\text { (unidade) }\end{array}$ & $\begin{array}{l}28,17 \\
(4,1)\end{array}$ & $\begin{array}{l}24,53 \\
(2,22)\end{array}$ & $\begin{array}{l}30,14 \\
(3,43)\end{array}$ & $\begin{array}{l}29,79 \\
(1,04)\end{array}$ & $\begin{array}{l}28,87 \\
(5,78)\end{array}$ & $\begin{array}{l}33,46 \\
(3,46)\end{array}$ \\
\hline $\begin{array}{l}\text { Receita Líquida de Vendas } \\
(\mathrm{R} \$ 1000)\end{array}$ & $\begin{array}{c}5169 \\
(2398) \\
\end{array}$ & $\begin{array}{c}4796 \\
(1338) \\
\end{array}$ & $\begin{array}{c}4541 \\
(1261) \\
\end{array}$ & $\begin{array}{l}3072 \\
(324)\end{array}$ & $\begin{array}{l}2012 \\
(661)\end{array}$ & $\begin{array}{c}4629 \\
(1136) \\
\end{array}$ \\
\hline Multinacional (\% estrangeiras) & 5,06 & 19,79 & 3,37 & 23,36 & 1,69 & 7,50 \\
\hline Grupo (\%) & 12,16 & 1,82 & 5,04 & 31,90 & 0,86 & 2,59 \\
\hline \multicolumn{7}{|c|}{ Indicadores de Esforço Inovativo } \\
\hline $\begin{array}{l}\text { Gastos com P\&D } \\
(\mathrm{R} \$ 1000)\end{array}$ & $\begin{array}{c}482,95 \\
(523,38) \\
\end{array}$ & $\begin{array}{c}287,21 \\
(336,89) \\
\end{array}$ & $\begin{array}{c}316,62 \\
(109,21) \\
\end{array}$ & $\begin{array}{c}31,1 \\
(36,15) \\
\end{array}$ & $\begin{array}{c}189,93 \\
(117,09) \\
\end{array}$ & $\begin{array}{r}394,77 \\
(562,41) \\
\end{array}$ \\
\hline $\begin{array}{l}\text { Gastos com Atividades } \\
\text { Inovativas }(\mathrm{R} \$ 1000)\end{array}$ & $\begin{array}{c}785,23 \\
(556,95) \\
\end{array}$ & $\begin{array}{c}532,38 \\
(344,24)\end{array}$ & $\begin{array}{c}563,18 \\
(163,63) \\
\end{array}$ & $\begin{array}{c}469,85 \\
(175,24)\end{array}$ & $\begin{array}{r}266,57 \\
(130,91) \\
\end{array}$ & $\begin{array}{c}591,6 \\
(587,85) \\
\end{array}$ \\
\hline $\begin{array}{l}\text { Proporção de Funcionários com } \\
3^{\circ} \text { Grau (unidade) }\end{array}$ & $\begin{array}{l}23,74 \\
(9,72)\end{array}$ & $\begin{array}{c}7,65 \\
(4,12) \\
\end{array}$ & $\begin{array}{c}8,09 \\
(1,76)\end{array}$ & $\begin{array}{c}1,2 \\
(0,69) \\
\end{array}$ & $\begin{array}{c}8,33 \\
(2,62) \\
\end{array}$ & $\begin{array}{c}5,59 \\
(7,75) \\
\end{array}$ \\
\hline Incubadora $(\%)$ & 14,53 & 26,03 & 10,69 & 46,88 & 3,30 & 3,98 \\
\hline P\&D Contínuo $(\%)$ & 9,04 & 7,86 & 11,20 & 56,70 & 6,43 & 3,59 \\
\hline Arranjo Cooperativo (\%) & 5,11 & 3,41 & 23,56 & 53,46 & 8,71 & 2,75 \\
\hline
\end{tabular}


Políticas de apoio à inovação em pequenas empresas: evidências sobre a experiência brasileira recente

Continuação

\begin{tabular}{l|c|c|c|c|c|c}
\hline Variáveis & $\begin{array}{c}\text { Incentivo } \\
\text { Fiscal } \\
\text { P\&D }\end{array}$ & $\begin{array}{c}\text { Incentivo } \\
\text { Fiscal } \\
\text { Informática }\end{array}$ & $\begin{array}{c}\text { Participação } \\
\text { em projetos } \\
\text { com parceria }\end{array}$ & $\begin{array}{c}\text { Financ, } \\
\text { Máquinas }\end{array}$ & Bolsas & $\begin{array}{c}\text { Capital } \\
\text { de Risco }\end{array}$ \\
\hline \multicolumn{7}{|c|}{ Indicadores de Resultado } \\
\hline $\begin{array}{l}\text { Produtividade do Trabalho } \\
\text { (R\$ 1000) }\end{array}$ & $\begin{array}{c}35,46 \\
(13,81)\end{array}$ & $\begin{array}{c}80,79 \\
(30,13)\end{array}$ & $\begin{array}{c}63,08 \\
(12,54)\end{array}$ & $\begin{array}{c}48,68 \\
(7,38)\end{array}$ & $\begin{array}{c}33,41 \\
(5,7)\end{array}$ & $\begin{array}{c}88,59 \\
(21,26)\end{array}$ \\
\hline Inovação de Produto (\%) & 3,99 & 10,60 & 5,82 & 50,83 & 1,08 & 1,83 \\
\hline Inovação de Processo (\%) & 2,69 & 7,42 & 3,34 & 67,51 & 1,12 & 2,57 \\
\hline Patente (\%) & 4,59 & 8,07 & 9,88 & 62,99 & 2,91 & 3,93 \\
\hline Proteção Formal (\%) & 6,92 & 5,49 & 11,09 & 57,21 & 7,21 & 6,71 \\
\hline Proteção Estratégica (\%) & 3,39 & 3,57 & 12,64 & 58,46 & 12,25 & 6,16 \\
\hline Inovação Organizacional (\%) & 1,57 & 8,28 & 4,93 & 58,37 & 2,83 & 3,38 \\
\hline Número Empresas (unidades) & 209 & 634 & 354 & 5.059 & 204 & 249 \\
\hline
\end{tabular}

Fonte: PINTEC (2010).

Os programas de bolsas de apoio à pesquisa destacam-se por concentrar empresas com maior proporção de funcionários com $3^{\circ}$ grau, mas com baixa produtividade do trabalho, com média de $\mathrm{R} \$ 33.410$ por trabalhador e baixa taxa de inovação em produto (1,08\% das empresas). Os programas de capital de risco atuaram, segundo a Pintec (2010), em um conjunto de 249 empresas, e destacam-se por englobar empresas, em média, com o maior número de trabalhadores $(33,46)$, e com elevada produtividade do trabalho, com média de $\mathrm{R} \$ 88.590$ por trabalhador.

Uma dimensão de análise importante na discussão de políticas de inovação para pequenas empresas diz respeito à distribuição desses recursos entre os setores de atividades industriais. A Tabela 6 apresenta o número de pequenas empresas inovadoras que se beneficiaram e as que não se beneficiaram de programas de apoio à inovação, segmentadas por setor de atividade.

As indústrias de transformação concentram o maior número de empresas beneficiadas, enquanto as indústrias extrativas apresentam um número bem reduzido de pequenas empresas participantes de programas públicos de apoio à inovação. De 2006 a 2008 as indústrias de transformação representavam 94,7\% do total das empresas apoiadas, já as indústrias extrativas representavam menos de $1 \%$ do total.

Dentre os setores da indústria de transformação, há uma diversidade de setores beneficiados e diferenças entre os períodos.

Comparando-se os três períodos, pode-se verificar que os setores de produção de Vestuário e Confecção e de produção de Alimentos apresentam os maiores números de empresas beneficiadas, enquanto que os setores com menos empresas apoiadas são o de produção de Fumo e de Celulose. 
Quanto à participação das empresas beneficiadas em relação ao total de empresas do setor, nota-se que, no período 2006-2008, cerca de $29 \%$ das empresas da amostra atuantes nos setores de Fármacos, Material para escritório e Informática e Material eletrônicos foram beneficiadas com programas de apoio à inovação. Por outro lado, os setores de Outros equipamentos de transporte $(2,7 \%)$, Couro e Calçados $(5,5 \%)$ e Têxtil $(6,2 \%)$ apresentaram as menores participações das beneficiadas em relação ao total de empresas do setor.

Ao se analisar o período 2001-2008 verifica-se que os setores em que houve maior crescimento da participação nos programas de apoio do governo foram Químicos e Minerais não metálicos, que saltaram de 89 para 518 empresas beneficiadas e de 91 para 531 empresas beneficiadas, respectivamente. Os setores que, por sua vez, apresentaram menor crescimento, ou seja, que tiveram menos apoio do governo para inovação, foram: Outros equipamentos de transporte e Peças e acessórios para veículos.

Portanto, considerando-se a evolução no período em análise, os dados indicam que não houve alterações significativas na abrangência setorial dos programas. Dentre os cinco setores com maior participação de empresas beneficiadas pelos programas, só há uma alteração importante entre 2000 e 2008, a de produtos Químicos, setor classificado como Intensivo em Ciência na taxonomia de Pavitt (1984).

Tabela 6

Número de Pequenas empresas inovadoras beneficiadas e não beneficiadas dos programas de apoio à inovação, segundo atividades selecionadas da indústria (*) - Brasil: período 2001-2008

\begin{tabular}{l|c|c|c|c|c|c}
\hline \multirow{2}{*}{ Total } & \multicolumn{2}{c|}{$2001-2003$} & \multicolumn{2}{c|}{$2003-2005$} & \multicolumn{2}{c}{$2006-2008$} \\
\cline { 2 - 7 } & Benef. & $\begin{array}{c}\text { Não } \\
\text { Benef. }\end{array}$ & Benef. & $\begin{array}{c}\text { Não } \\
\text { Benef. }\end{array}$ & Benef. & $\begin{array}{c}\text { Não } \\
\text { Benef. }\end{array}$ \\
\hline Indústrias extrativas & 4510 & 48718 & 4645 & 54719 & 8367 & 64280 \\
\hline Indústrias de transformação & 41 & 774 & 35 & 816 & 60 & 1094 \\
\hline Alimentos & 448 & 47944 & 4322 & 51607 & 7923 & 58929 \\
\hline Bebidas & 581 & 4882 & 475 & 5641 & 953 & 6628 \\
\hline Fumo & 28 & 362 & 52 & 442 & 62 & 350 \\
\hline Têxtil & - & 10 & & 23 & - & - \\
\hline Vestuário e Confecção & 111 & 1858 & 246 & 2380 & 142 & 2124 \\
\hline Couro e Calçados & 618 & 8437 & 539 & 8542 & 1207 & 9799 \\
\hline Madeira & 101 & 2344 & 217 & 2546 & 193 & 3303 \\
\hline & 200 & 2691 & 139 & 2524 & 354 & 2671 \\
\hline
\end{tabular}


Políticas de apoio à inovação em pequenas empresas: evidências sobre a experiência brasileira recente

Continuação

\begin{tabular}{|c|c|c|c|c|c|c|}
\hline & \multicolumn{2}{|c|}{$2001-2003$} & \multicolumn{2}{|c|}{$2003-2005$} & \multicolumn{2}{|c|}{$2006-2008$} \\
\hline & Benef. & $\begin{array}{l}\text { Não } \\
\text { Benef. }\end{array}$ & Benef. & $\begin{array}{l}\text { Não } \\
\text { Benef. }\end{array}$ & Benef. & $\begin{array}{c}\text { Não } \\
\text { Benef. }\end{array}$ \\
\hline Celulose e Papel & 85 & 925 & 16 & 986 & 80 & 1073 \\
\hline Celulose & 1 & 6 & 1 & 9 & - & - \\
\hline Papel e Produtos de Papel & 84 & 919 & 15 & 976 & 80 & 1073 \\
\hline Edição e impressão & 234 & 2213 & 280 & 2593 & 441 & 2010 \\
\hline $\begin{array}{l}\text { Coque, Refino de Petróleo, } \\
\text { Nucleares }\end{array}$ & - & 63 & 3 & 40 & 18 & 89 \\
\hline Coque e bicombustível & - & 18 & 1 & 7 & 14 & 53 \\
\hline Refino de petróleo & - & 45 & 2 & 33 & 4 & 36 \\
\hline Químicos & 126 & 2060 & 229 & 2191 & 602 & 2154 \\
\hline Químicos & 89 & 1707 & 202 & 1863 & 518 & 1950 \\
\hline Farmacêuticos & 37 & 353 & 27 & 328 & 83 & 203 \\
\hline Artigos de Borracha & 387 & 2949 & 405 & 2875 & 451 & 3709 \\
\hline Minerais não metálicos & 91 & 3241 & 244 & 3317 & 531 & 4634 \\
\hline Metalurgia Básica & 55 & 800 & 79 & 771 & 66 & 789 \\
\hline Siderurgia & 15 & 169 & 11 & 134 & 20 & 278 \\
\hline Metais não ferrosos & 40 & 631 & 68 & 637 & 45 & 511 \\
\hline Produtos de Metal & 470 & 4079 & 338 & 4771 & 861 & 6349 \\
\hline Máquinas e Equipamentos & 375 & 3088 & 301 & 3746 & 625 & 3283 \\
\hline $\begin{array}{l}\text { Máquinas p/ Escritório e } \\
\text { Informática }\end{array}$ & 45 & 91 & 47 & 114 & 43 & 101 \\
\hline $\begin{array}{l}\text { Máquinas e Equipamentos } \\
\text { Elétricos }\end{array}$ & 175 & 990 & 161 & 1083 & 204 & 1027 \\
\hline $\begin{array}{l}\text { Material Eletrônico, Equip. } \\
\text { Comun. }\end{array}$ & 57 & 367 & 77 & 339 & 98 & 328 \\
\hline Material eletrônico & 39 & 200 & 48 & 192 & 74 & 179 \\
\hline Equip. de comunicação & 18 & 166 & 28 & 146 & 24 & 149 \\
\hline $\begin{array}{l}\text { Equip. Instrumentação de } \\
\text { Precisão e Ópticos, para } \\
\text { Automação Industrial }\end{array}$ & 45 & 568 & 103 & 598 & 44 & 408 \\
\hline Veículos automotores & 116 & 1031 & 57 & 1101 & 120 & 1524 \\
\hline $\begin{array}{l}\text { Automóveis, caminhões e } \\
\text { ônibus }\end{array}$ & - & 7 & 1 & 6 & 1 & 12 \\
\hline $\begin{array}{l}\text { Cabines, carrocerias e } \\
\text { reboques }\end{array}$ & 39 & 432 & 12 & 379 & 80 & 742 \\
\hline $\begin{array}{l}\text { Peças e acessórios para } \\
\text { veículos }\end{array}$ & 76 & 592 & 44 & 716 & 39 & 770 \\
\hline $\begin{array}{l}\text { Outros Equipamentos de } \\
\text { Transporte }\end{array}$ & 17 & 296 & 19 & 264 & 7 & 246 \\
\hline Móveis & 342 & 3338 & 224 & 3385 & 399 & 3346 \\
\hline Produtos diversos & 181 & 1179 & 72 & 1184 & 310 & 1660 \\
\hline
\end{tabular}

Fonte: IBGE. (*) A classificação setorial utilizada nesse estudo é a Classificação Nacional de Atividades Econômicas (CNAE) 1.0. 
Ao se analisar os diferentes tipos de programas (Tabela 1A em anexo), verifica-se que as indústrias extrativas concentram-se na participação de programas de apoio à aquisição de máquinas e equipamentos para inovação, enquanto que as indústrias de transformação apresentam uma participação mais ampla, abrangendo a diversidade de programas de apoio à inovação disponíveis na atualidade.

O programa de incentivo fiscal para atividades de $\mathrm{P} \& \mathrm{D}$ apoiou um número maior de empresas atuantes nos setores de Vestuário e Confecção e produção de Madeira. Quanto ao programa de incentivo fiscal aos setores de informática, verificase que os setores de Máquinas para escritório e informática e Máquinas e equipamentos eletrônicos apresentam um número elevado de empresas beneficiadas.

Os setores mais contemplados pelos programas de apoio às atividades inovativas com parcerias com Universidades e centros de pesquisa foram os setores de produtos Químicos, Madeira e Vestuário e confecção. Observa-se pela Tabela 1A que esse programa ainda é pouco representativo e reduziu no período analisado, de 2001 a 2008, o número de empresas beneficiadas, que passou de 395 em 2001-2003 para 325 pequenas empresas beneficiadas entre os anos 2006 e 2008.

Os programas de financiamento para aquisição de máquinas e equipamentos para inovação destacam-se por serem programas de maior abrangência dentre as pequenas empresas beneficiadas. Das 5.058 empresas beneficiadas, 740 empresas atuam no setor de Vestuário e Confecção, 717 empresas na produção de Alimentos e 627 empresas na produção de Produtos de Metal. A maior participação destes setores neste programa em 2008 não se altera em relação à sua participação no ano de 2000 .

Em síntese, pode-se afirmar que a política de apoio à inovação no Brasil vem apresentando resultados positivos na ampliação do escopo de instrumentos e do volume de recursos, atingindo, assim, empresas de menor porte.

Uma evidência que merece destaque refere-se ao comportamento dos indicadores de esforço e desempenho inovativos das pequenas empresas contempladas pelos programas de apoio à inovação superiores aos indicadores das não contempladas. As empresas de pequeno porte estão apresentando esforço inovativo superior à amostra total de empresas e, em grande medida, esse indicador positivo pode ser resultado de uma maior abrangência e efetividade das políticas destinadas a esse segmento de empresas.

Entretanto, do ponto de vista da abrangência setorial dos programas não se verifica alterações importantes no período analisado, conforme já destacado. É possível que este resultado se deva ao fato de que parte importante dos programas foi implementada nos últimos anos, no âmbito da PDP e PBM, não captados integralmente nos dados da Pintec 2008. Ademais, como os programas de apoio 
visam mudanças de longo prazo, parte dos resultados só é verificável em períodos de análise maiores.

\section{Considerações finais}

Assiste-se, nos últimos anos, a mudanças importantes no aparato de apoio à indústria, nos países desenvolvidos e em desenvolvimento. A partir de estudos que relacionam, por meio de metodologias distintas, crescimento econômico e progresso tecnológico, verifica-se crescente importância ao apoio, direto e indireto, às atividades inovativas das empresas.

$\mathrm{O}$ apoio às atividades inovativas tem crescido, tanto em termos de magnitude dos recursos envolvidos quanto em termos de diversificação dos instrumentos. As principais diretrizes referem-se ao fortalecimento e coordenação de ações visando criar um ambiente mais favorável às atividades inovativas e, com respeito às pequenas e médias empresas, promover a redução de custos para a criação de empresas, promover a inovação por meio de medidas de apoio direto e do estabelecimento de regimes fiscais mais favoráveis às empresas inovadoras, e melhorar o acesso dessas empresas ao sistema financeiro.

A partir do início dos anos 2000, com as diretrizes da Pitce e da PDP, e de mudanças na legislação relacionadas a essas diretrizes (Lei de Inovação, Lei do Bem e Lei de Informática), um conjunto de instrumentos de apoio à inovação em PEs começa a ser definido e implementado no Brasil.

O presente artigo contribui para analisar essas mudanças ao mostrar que:

- O conjunto de instrumentos abarca um contingente cada vez maior de empresas ao longo do tempo, o que é um indicador importante de uma demanda reprimida e da contribuição das políticas públicas. Houve um aumento da participação das empresas inovadoras, independente do porte, nos programas de apoio do governo. Em relação às PEs, o percentual de empresas inovadoras beneficiadas passou de 82\% para 86\% entre 2003 e 2008 (Pintec, 2005; 2010).

- Os dados permitem realizar uma avaliação dos programas que, embora em caráter exploratório, mostram as diferenças de esforço e de desempenho inovativos de empresas beneficiadas e não beneficiadas. Os dados analisados mostram que as empresas beneficiadas, independente do porte, apresentam indicadores de esforço inovativo (gastos em P\&D, gastos em atividades inovativas e proporção de funcionários com $3^{\circ}$ grau completo, P\&D contínuo) superiores às empresas não beneficiadas. A superioridade permanece no que se refere aos indicadores de desempenho inovativo, dado que as empresas de todos os portes que receberam suporte do governo apresentam produtividade do trabalho e índice de patenteamento superiores ao grupo das não beneficiadas. 
Quando se analisa o recorte por tipo de programa - incentivos fiscais e financeiros - os indicadores de desempenho do conjunto de empresas beneficiadas pelos incentivos financeiros mostram que nas pequenas empresas o patenteamento $(73,17 \%)$ e a proteção estratégica $(73,05 \%)$ são mais elevados que nas empresas de médio e grande porte beneficiadas por esses mesmos incentivos.

- Quando se considera os esforços inovativos das pequenas empresas, verifica-se que são distintos do conjunto das empresas de maior porte. As PEs beneficiadas pelos incentivos fiscais apresentam como indicadores principais de esforço inovativo aqueles mais convencionalmente tratados na literatura, como gastos em P\&D, gastos em atividades inovativas e proporção de funcionários com $3^{\circ}$ grau completo. Ademais, esses indicadores são superiores ao grupo das pequenas empresas beneficiadas pelos incentivos financeiros.

Também quanto ao tipo de programa de apoio à inovação, constata-se que há diferenças entre os portes. As PEs que receberam incentivos financeiros apresentam, além de indicadores de esforço inovativo mais elevados, fontes mais diversificadas para a inovação, como maior participação em arranjos cooperativos, participação em incubadoras e realização de P\&D contínuo. Este resultado corrobora as evidências encontradas para outros países, como discutido na seção 1 .

- A diversificação de instrumentos de apoio à inovação é essencial para abarcar o segmento das empresas de pequeno porte, dadas as evidências empíricas de que estas empresas apresentam esforços inovativos que as diferenciam das grandes empresas. Verifica-se a existência de um amplo espectro de atitudes - innovative firms without $R \& D$, gastos de $\mathrm{P} \& \mathrm{D}$ proporcionalmente mais elevados que as grandes empresas, combinação de fontes internas e externas de conhecimento -, reflexo da heterogeneidade que caracteriza este segmento de empresas. Como decorrência, aparatos de apoio concentrados em um único instrumento, incentivos fiscais ou capital de risco, por exemplo, tendem a ser pouco eficazes para o estímulo à inovação em PEs.

- A análise das empresas beneficiadas, segundo setores de atividade produtiva, indicou poucos avanços na abrangência setorial dos programas ao longo do período em análise. Os principais setores apoiados são os mesmos entre 2000 e 2008, e o principal instrumento de apoio a estes setores também é o mesmo: o financiamento à aquisição de máquinas e equipamentos.

Os resultados deste estudo mostram, portanto, além do aumento importante da participação das empresas de pequeno porte nos programas públicos, que a diversidade de programas está atingindo empresas inovadoras desse porte. Exaltase que, além da grande participação dessas empresas em programas de 
financiamento para aquisição de máquinas e equipamentos, há também grande participação das pequenas empresas em instrumentos de apoio como participação em projetos com parceria, bolsas de apoio a pesquisadores e participação em programas de capital de risco.

Entretanto, dado o pouco tempo transcorrido desde a implementação dos programas de apoio, torna-se necessário avaliar os resultados com cautela e indicar a necessidade de futuros trabalhos que façam o acompanhamento da evolução das empresas contempladas por recursos públicos.

Nesse sentido, a maior abrangência e efetividade dos programas de apoio à inovação em PEs brasileiras nos últimos anos, mostradas neste trabalho, não implica em considerá-los suficientes. Há ainda um contingente muito elevado de empresas não contempladas pelos programas, assim como programas que não conseguem atingir o público alvo na magnitude planejada, aspecto que foge ao escopo deste trabalho, mas que constitui um importante elemento para uma agenda futura de pesquisa.

\section{Referências bibliográficas}

ACS, Z. J.; AUDRETSCH, D. B. Innovation and small firms. Cambridge, Massachussetts: MIT Press, 1990.

ALBUQUERQUE, E. M. Catching up no século XXI: construção combinada de sistemas de inovação e de bem-estar social. Crescimento econômico: estratégias e instituições. Ipea, 2009. p. 55-83.

ASHEIM, B.; GERTLER, M. S. The geography of innovation: regional innovation systems. The Oxford handbook of innovation. Oxford: Oxford University Press, 2006.

AUDRETSCH, D. Sustaining innovation and growth: public policy support for entrepreneurship. Industry and Innovation, v. 11, n. 3, p. 167-194, 2004.

AVELlaR, A. P.; ALVES, P. Avaliação de impacto de Programas de Incentivos Fiscais à Inovação - Um estudo sobre os efeitos do PDTI no Brasil. Revista Economia ANPEC, v. 9, n. 1, p. 143-164, 2008.

BAPTISTA, R.; SWANN, P. Do firms in clusters innovate more? Research Policy, n. 27, p. 525-540, 1998.

BECK, T.; DEMIRGUC-KUNT, A. Small and medium-size enterprises: access to finance as a growth constraint. Journal of Banking \& Finance, n. 30, p. 2931-2943, 2006.

BIANCHI, P.; LABORY, S. Industrial policy after the crisis. Edgar Elgar, 2011. 
BLOOM, N.; GRIFFITH, R.; VAN REENEN, J. Do R\&D tax credit work? Evidence form a panel of countries 1979-1997. Journal of Public Economics, n. 85, p. 1-31, 2002.

BOTELHO, M. R. A.; MAIA, A. F. S.; PIRES, L. A. V. Inovação e porte das empresas: evidências sobre a experiência nacional e estrangeira. In: ENCONTRO DA SOCIEDADE DE ECONOMIA POLÍTICA, 16, 2011. Anais...

CAINELLI, G.; DE LISO, N. Innovation and industrial districts: evidence from Italy. Industry and Innovation, v. 12, n. 3, p. 383-398, 2005.

CANO, W.; SILVA, A. L. G. Política industrial do governo Lula. Campinas: IE/Unicamp, 2010. (Texto para Discussão, n. 181).

CARBINATO, D.; CORRÊA, D. Política de desenvolvimento produtivo: avaliação crítica. Informações FIPE, p. 28-34, 2008.

CASSIOLATO, J. E.; LASTRES, H. M. M. O foco em arranjos produtivos e inovativos locais de micro e pequenas empresas. In: LASTRES, H. M. M.; CASSIOLATO, J. E.; MACIEL, M. L. (Org.). Pequena empresa - Cooperação e desenvolvimento local. Rio de Janeiro: Ed. Relume Dumará, 2003.

COM. Towards a more effective use of tax incentives in favour of $R \& D$. COMMISSION OF THE EUROPEAN COMMUNITIES, 2006.

. Removing obstacles to cross-border investments by venture capital funds. COMMISSION OF THE EUROPEAN COMMUNITIES, 2007.

CZARNITZKI, D.; HANEL, P.; ROSA, J. M. Evaluations the impact of R\&D tax credits on innovation: a microeconometric study on Canadian firms. Centre for European Economic Research, Nov. 2004. (ZEW Discussion Paper, n. 04-77). Disponível em: http://callisto.si.usherb.ca:8080/gredi/wpapers/GREDI-0501.pdf.

; HOTTENROTT, H. R\&D investment and financing constraints of small and medium-sized firms. Small Business Economics, 36, p. 65-83, 2011.

DAVID, P. A.; HALL, B. H.; TOOLE, A. A. Is public R\&D a complement or substitute for private $\mathrm{R} \& \mathrm{D}$ ? A review of the econometric evidence. Research Policy, n. 29, p. 497-529, 2000.

DINI, M.; STUMPO, G. Políticas para la innovación en las pequeñas y medianas empresas en América Latina. Chile: Nações Unidas, 2011.

ELSTON, J. A.; AUDRETSCH, D. Financing the entrepreneurial decision: an empirical approach using experimental data on risk attitudes. Small Business Economics, 36, p. 209-222, 2011. 
FATOKI, O. O.; SMIT, A. V. A. Constraints to credit access by new SMEs in South Africa: a supply-side analysis. African Journal of Business Management, v. 5, n. 4, p. 1413-1425, 2011.

FREEMAN, C. Networks of innovators: a synthesis of research issues. Research Policy, n. 20, p. 499-514, 1991.

FERRARO, C, (Org.). Apoyando a las pymes: políticas de fomento en América Latina y el Caribe. Chile: Nações Unidas, 2011.

GRIFFITH, R.; REDDING, S.; VAN REENEN, J. Measuring the cost effectiveness of an R\&D tax credit for the UK. London School of Economics and Political Science. Center for Economic Performance, 2000.

HALL, B. The financing of research and development. Cambridge, MA: NBER, 2002. (NBER Working Paper Series, Working Paper, 8773).

; VAN REENEN, J. How effective are fiscal incentives for R\&D? A review of the evidence. Research Policy, 29, p. 449-469, 2000.

IEDI. Incentivos para inovação. O que falta ao Brasil. Instituto de Estudos de Desenvolvimento Industrial, 2010.

LERNER, J. The government as venture capitalist: the long-run effects of the SBIR Program. Journal of Business, 72, p. 285-318, 1999.

LIMING, W. The SME financing gap: theory and practice. Disponível em: http://ieeexplore.ieee.org/xpls/abs_all.jsp?arnumber=5882262. Acesso em: 11 jul. 2012.

KAUFMANN, A.; TÖDLING, F. How effective is innovation support for SMEs? An analysis of the region Upper Austria. Technovation, n. 22, p. 147-159, 2002.

LAPLANE, M.; SARTI, F. Prometeu acorrentado: o Brasil na indústria mundial no início do século XXI. 2006. Disponível em: http://www.iececon.net/PEF/Secao_IX07PEF.pdf. Acesso em; jun. 2014.

LUNDVALL, B. A. (Ed.). National Systems of Innovation: towards a theory of innovation and interactive learning. London: Pinter Publishers, 1992.

MATOS, M.; ARROIO, A. Políticas de apoio a micro e pequenas empresas no Brasil: avanços no período recente e perspectivas futuras. Chile: Nações Unidas, 2011.

MCTI. Indicadores Nacionais de Ciência, Tecnologia e Inovação. Disponível em: http://www.mcti.gov.br/index.php/content/view/740.html?execview=. Acesso em: 3 jun. 2014. 
MCTI. Estratégia Nacional de Ciência, Tecnologia e Inovação: 2012-2015. Brasília: Balanço das Atividades Estruturantes 2011, 2012.

MEULEMAN, M.; DE MAESENEIRE, W. Do R\&D subsidies affect SMEs' access to external financing? Research Policy, 41, p. 580-591, 2012.

MYTELKA, L.; FARINELLI, F. Local clusters, innovation systems and sustained competitiveness. Maastricht, The Netherlands: United Nations University, Institute for New Technologies, 2000.

NARETTO, N.; BOTELHO, M. R. A.; MENDONÇA, M. A trajetória das políticas públicas para pequenas e médias empresas no Brasil: do apoio individual ao apoio a empresas articuladas em arranjos produtivos locais. Planejamento e Políticas Públicas, n. 27, p. 61-115, 2004.

NAWELAERS, C.; WINTJES, R. SME policy and the regional dimension of innovation: towards a new paradigm of innovation policy? s.d. Disponível em: http://arno.unimaas.nl/show.cgi?fid=274. Acesso em: 6 mar. 2012.

OECD. Boosting innovation - The cluster approach. Paris: Organization for Economic Cooperation and Development, 1999.

Science and innovation policy. Paris: Organization for Economic Cooperation and Development, 2004.

The SME financing gap. Paris: Organization for Economic Cooperation and Development, 2006.

. Competitive regional clusters - National policy approaches. Paris: Organization for Economic Cooperation and Development, 2007.

. The OECD innovation strategy: innovation to strengthen growth and address global and social challenges. Paris: OCDE Publications, 2010.

PAVITT, K. Sectoral patterns of technical change: toward a taxonomy and a theory. Research Policy, 13, p. 343-373, 1984.

; ROBSON, M.; TOWNSEND, J. The size distribution of innovating firms in the UK: 1945-1983. Journal of Industrial Economics, v. 35, n. 3, p. 297-316, 1987.

PINTEC. Pesquisa de Inovação Tecnológica. Rio de Janeiro: Instituto Brasileiro de Geografia e Estatística, 2005, 2007 e 2010.

SALLES FILHO, S.; BONACELLI, M. B.; CARNEIRO, A. M.; CASTRO, P. F. D.; SANTOS, F. O. Evaluation of ST\&I programs: a methodological approach to the Brazilian Small Business Program and some comparisons with the SBIR program. Research Evaluation, v. 20, n. 2, p. 159-171, 2011. 
SANTARELLI, E.; PIERGIOVANNI, R. Analyzing literature-based innovation output indicators: the Italian experience. Research Policy, 25, p. 689-711, 1996.

SCHAPIRO, M. G. Ativismo estatal e industrialismo defensivo: instrumentos e capacidades na política industrial brasileira. In: GOMIDE, A. A.; PIRES, R. R. C. Capacidades estatais e democracia: arranjos institucionais de políticas públicas. Brasília: Ipea, 2014.

SCHMITZ, H.; NADVI, K. Clustering and industrialization: introduction. World Development, v. 27, n. 9, 1999.

SOUZA, M. C. A. F.; BOTELHO, M. R. A. Reflexões sobre as políticas de apoio às pequenas empresas brasileiras no período recente. Ensaios FEE, v. 22, n. 1, p. 115 $142,2001$.

STEINDL, J. Pequeno e grande capital. São Paulo: Hucitec, 1990.

Maturidade e estagnação no capitalismo americano. Rio de Janeiro: Graal, 1983.

SUZIGAN, W. A política industrial brasileira após uma década de estagnação. Economia e Sociedade, Campinas, n. 1, p. 89-110, ago. 1992.

; SOUZA, M. C. A. F. Política industrial e pequenas e médias empresas no Brasil. Campinas, 1990. Mimeografado.

UK. HM Treasury. Supporting growth in innovation: enhancing the R\&D tax credit. Jul. 2005.

VAONA A.; PIANTA, M. Firm size and innovation in European manufacturing. Small Business Economics, n. 30, p. 283-299, 2008.

VON TUNZELMANN, N.; ACHA, V. Innovation in "low-tech" industries. The Oxford Handbook of Innovation. Oxford: Oxford University Press, 2006.

WARDA, J. An update of R\&D tax treatment in OECD countries and selected emerging economies, 2008-2009. OECD Science, Technology and Industry Scoreboard, 2009.

WU, J.; SONG, J.; ZENG, C. An empirical evidence of small business financing in China. Management Research News, v. 31, n. 12, p. 959-975, 2008. 


\section{Anexo}

Tabela $1 \mathrm{~A}$

Número de pequenas empresas inovadoras beneficiadas dos programas de apoio à inovação, segundo atividades selecionadas da indústria - Brasil: período 2001-2008

\begin{tabular}{|c|c|c|c|c|c|c|c|c|c|c|c|c|c|c|c|c|c|}
\hline & \multicolumn{5}{|c|}{ 2001-2003 } & \multicolumn{5}{|c|}{ 2003-2005 } & \multicolumn{7}{|c|}{ 2006-2008 } \\
\hline & \multicolumn{2}{|c|}{ Incentivo fiscal } & \multicolumn{2}{|c|}{ Financiamento } & \multirow{3}{*}{$\begin{array}{c}\text { Outros } \\
(*)\end{array}$} & \multicolumn{2}{|c|}{ Incentivo fiscal } & \multicolumn{2}{|c|}{ Financiamento } & \multirow{3}{*}{ Outros } & \multicolumn{2}{|c|}{ Incentivo fiscal } & \multirow{3}{*}{$\begin{array}{c}\text { Subvenção } \\
\text { econômica } \\
(* *)\end{array}$} & \multicolumn{3}{|c|}{ Financiamento } & \multirow{3}{*}{ Outros } \\
\hline & & & & & & & & & & & & & & & & $M \& E$ & \\
\hline & P\&D & Infor. & rias & $M \& E$ & & $P \& D$ & Infor. & rias & M\&E & & $P \& D$ & Infor. & & $\begin{array}{c}\text { Sem } \\
\text { Parceria }\end{array}$ & $\begin{array}{c}\text { Com } \\
\text { Parceria } \\
\end{array}$ & & \\
\hline Total & 107 & 167 & 396 & 3305 & 103 & 82 & 283 & 300 & 2794 & 47 & 209 & 634 & 301 & 471 & 354 & 5059 & 2892 \\
\hline Indústrias extrativas & - & - & 1 & 41 & - & - & - & 6 & 22 & - & - & - & 1 & 4 & - & 16 & 39 \\
\hline Indústrias de transformação & 107 & 167 & 395 & 3265 & 103 & 53 & 201 & 261 & 2680 & 27 & 193 & 616 & 216 & 439 & 325 & 4954 & 2644 \\
\hline Alimentos & - & 10 & 64 & 352 & 27 & 6 & 9 & 70 & 272 & - & 4 & 87 & 4 & 72 & 14 & 717 & 233 \\
\hline Bebidas & 3 & - & - & 4 & - & - & - & - & 30 & - & - & - & - & 6 & - & 45 & 59 \\
\hline Fumo & - & - & - & - & - & - & - & - & - & - & - & - & - & - & - & - & - \\
\hline Têxtil & - & - & 1 & 77 & 1 & - & - & 5 & 143 & - & 22 & - & - & - & 2 & 70 & 52 \\
\hline Vestuário e Confecção & 31 & 8 & - & 540 & - & 10 & 45 & 30 & 333 & - & - & 35 & 39 & 36 & 39 & 740 & 453 \\
\hline Couro e Calçados & - & - & 4 & 67 & - & 4 & 4 & 6 & 202 & - & - & - & - & 6 & 28 & 103 & 124 \\
\hline Madeira & 29 & - & 39 & 159 & - & 1 & - & - & 24 & - & - & 92 & - & 89 & 54 & 128 & 135 \\
\hline Celulose e Papel & - & - & - & 82 & - & - & - & - & 8 & - & - & 16 & 2 & 16 & - & 59 & 11 \\
\hline Celulose & - & - & - & 1 & - & - & - & - & - & - & - & - & - & - & - & - & - \\
\hline Papel e produtos de papel & - & - & - & 81 & - & - & - & - & 8 & - & - & 16 & 2 & 16 & - & 59 & 11 \\
\hline Edição e Impressão & 25 & - & 47 & 157 & - & - & - & - & 165 & - & - & 68 & 1 & - & - & 380 & 116 \\
\hline $\begin{array}{l}\text { Coque, Refino de Petróleo, } \\
\text { Nucleares }\end{array}$ & - & - & - & - & - & - & - & 2 & 2 & 2 & - & - & - & - & - & 12 & 8 \\
\hline Coque e biocombustível & - & - & - & - & - & - & - & - & - & - & - & - & - & - & - & 12 & 4 \\
\hline Refino de petróleo & - & - & - & - & - & - & - & 2 & 2 & 2 & - & - & - & - & - & - & 4 \\
\hline Químicos & 12 & - & 4 & 95 & 1 & 6 & - & 13 & 187 & 7 & & & & & & & \\
\hline Químicos & 12 & - & 3 & 65 & - & 5 & - & 13 & 162 & 7 & 1 & 3 & 103 & 103 & 82 & 186 & 239 \\
\hline Farmacêuticos & - & - & 1 & 30 & 1 & 1 & - & - & 26 & - & - & - & 6 & - & 25 & 62 & 36 \\
\hline Artigos de Borracha & - & - & 33 & 352 & 19 & - & 3 & 25 & 296 & - & 93 & - & 14 & 20 & 13 & 219 & 165 \\
\hline Minerais não Metálicos & - & - & 7 & 75 & - & - & - & 4 & 160 & - & 4 & 4 & - & - & - & 451 & 80 \\
\hline Metalurgia Básica & - & - & 38 & 17 & 5 & 1 & - & 3 & 75 & 3 & 7 & - & - & - & 2 & 59 & 7 \\
\hline Siderurgia & - & - & 15 & - & 5 & 1 & - & 2 & 10 & - & 7 & - & - & - & - & 19 & 4 \\
\hline Metais não ferrosos & - & - & 23 & 17 & - & - & - & 1 & 65 & 3 & - & - & - & - & 2 & 41 & 3 \\
\hline
\end{tabular}

Economia e Sociedade, Campinas, v. 24, n. 2 (54), p. 379-49ntinua.... 2015. 
Políticas de apoio à inovação em pequenas empresas: evidências sobre a experiência brasileira recente

\begin{tabular}{|c|c|c|c|c|c|c|c|c|c|c|c|c|c|c|c|c|c|}
\hline & \multicolumn{5}{|c|}{ 2001-2003 } & \multicolumn{5}{|c|}{ 2003-2005 } & \multicolumn{7}{|c|}{ 2006-2008 } \\
\hline & \multicolumn{2}{|c|}{ Incentivo fiscal } & \multicolumn{2}{|c|}{ Financiamento } & \multirow{3}{*}{$\begin{array}{c}\text { Outros } \\
\left(^{*}\right)\end{array}$} & \multicolumn{2}{|c|}{ Incentivo fiscal } & \multicolumn{2}{|c|}{ Financiamento } & \multirow{3}{*}{ Outros } & \multicolumn{2}{|c|}{ Incentivo fiscal } & \multirow{3}{*}{$\begin{array}{c}\begin{array}{c}\text { Subvenção } \\
\text { econômica } \\
(* *)\end{array} \\
\end{array}$} & \multicolumn{3}{|c|}{ Financiamento } & \multirow{3}{*}{ Outros } \\
\hline & & & & & & & & & & & \multirow[b]{2}{*}{$P \& D$} & \multirow[b]{2}{*}{ Infor. } & & \multicolumn{2}{|c|}{$\mathrm{P} \& \mathrm{D}$} & \multirow[t]{2}{*}{ M\&E } & \\
\hline & P\&D & Infor. & rias & $M \& E$ & & $P \& D$ & Infor. & rias & M\&E & & & & & $\begin{array}{c}\text { Sem } \\
\text { Parceria }\end{array}$ & $\begin{array}{c}\text { Com } \\
\text { Parceria }\end{array}$ & & \\
\hline Produtos de Metal & - & - & 18 & 402 & - & 4 & 1 & 4 & 120 & - & 23 & 35 & - & 17 & 5 & 627 & 297 \\
\hline Máquinas e Equipamentos & 1 & 25 & 34 & 267 & 1 & 1 & 15 & 9 & 226 & 2 & 1 & 3 & 1 & 1 & 13 & 450 & 163 \\
\hline $\begin{array}{l}\text { Máquinas p/ Escritório e } \\
\text { Informática }\end{array}$ & 1 & 43 & 2 & 2 & 2 & 3 & 45 & 2 & 4 & 1 & 5 & 36 & 2 & 3 & 21 & 1 & 8 \\
\hline $\begin{array}{l}\text { Máquinas e Equipamentos } \\
\text { Elétricos }\end{array}$ & 1 & 33 & 22 & 122 & 2 & 8 & 27 & 54 & 65 & 3 & 17 & 34 & 16 & 8 & 10 & 94 & 67 \\
\hline $\begin{array}{l}\text { Material Eletrônico, Equip. } \\
\text { Comun. }\end{array}$ & 3 & 29 & 4 & 23 & 1 & 3 & 26 & 13 & 44 & 1 & 4 & 39 & 14 & 27 & 3 & 20 & 21 \\
\hline Material eletrônico & 2 & 21 & 3 & 18 & - & - & 11 & 9 & 28 & - & 2 & 28 & 2 & 22 & - & 18 & 16 \\
\hline Equip. de comunicação & 1 & 8 & 1 & 5 & 1 & 3 & 15 & 5 & 16 & 1 & 2 & 10 & 12 & 5 & 3 & 1 & 5 \\
\hline $\begin{array}{l}\text { Equip. Instrumentação de } \\
\text { Precisão e Ópticos, p. } \\
\text { Automação Industrial }\end{array}$ & - & 10 & - & 12 & 1 & 3 & 26 & 10 & 66 & 1 & 8 & 19 & 8 & 7 & 7 & 4 & 20 \\
\hline Veículos Automotores & - & 9 & 4 & 116 & 9 & 3 & - & - & 52 & - & 2 & 3 & - & 4 & 1 & 108 & 9 \\
\hline $\begin{array}{l}\text { Automóveis, caminhões e } \\
\text { ônibus }\end{array}$ & - & - & - & - & - & - & - & - & - & - & - & - & - & - & - & 1 & - \\
\hline $\begin{array}{l}\text { Cabines, carrocerias e } \\
\text { reboques }\end{array}$ & - & - & - & 39 & - & 3 & - & - & 9 & - & - & - & - & - & - & 76 & 6 \\
\hline $\begin{array}{l}\text { Peças e acessórios para } \\
\text { veículos }\end{array}$ & - & 9 & 4 & 76 & 9 & - & - & - & 43 & - & 2 & 3 & - & 4 & 1 & 30 & 3 \\
\hline $\begin{array}{l}\text { Outros Equipamentos de } \\
\text { Transporte }\end{array}$ & - & - & 15 & 2 & - & - & 1 & - & 17 & - & - & - & - & - & - & 5 & 2 \\
\hline Móveis & - & - & 58 & 238 & - & - & - & 3 & 127 & 7 & - & 54 & - & - & - & 172 & 227 \\
\hline Produtos diversos & - & 1 & 1 & 105 & 33 & 1 & 1 & 8 & 62 & - & 2 & 87 & 3 & 20 & 6 & 173 & 76 \\
\hline
\end{tabular}

Fonte: IBGE. (*) Em Outros programas estão incluídos programas de apoio ao pesquisador na empresa como o programa RHAE/CNPq e os programas de capital de risco. (**) Programas de subvenção econômica só passaram a ser computados na Pintec (2008). 